Aus dem Department für Nutztierwissenschaften

Lehrstuhl Aquakultur und Gewässerökologie

\title{
Quantitative and molecular genetic studies on temperature-dependent sex determination of Nile tilapia (Oreochromis niloticus)
}

\author{
Dissertation \\ zur Erlangung des Doktorgrades \\ der Fakultät für Agrarwissenschaften \\ der Georg-August-Universität Göttingen
}

vorgelegt von

Liane-Magdalena Lühmann

geboren in Celle 
D7

1. Referentin: Prof. Dr. Gabriele Hörstgen-Schwark

2. Korreferent: Prof. Dr. Christoph Knorr

Tag der mündlichen Prüfung: 02. Februar 2012 


\section{Table of Contents}

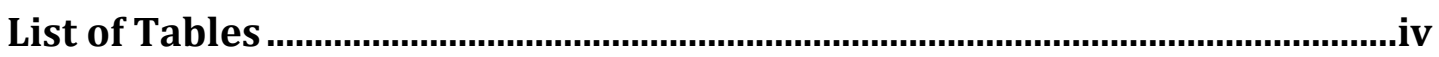

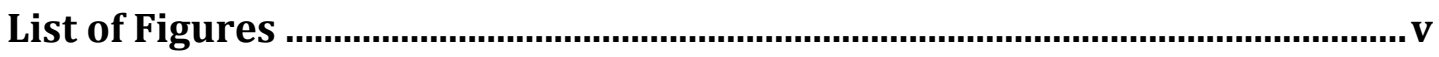

List of Publications ...................................................................................................vi

List of Conference Contributions ..........................................................................vi

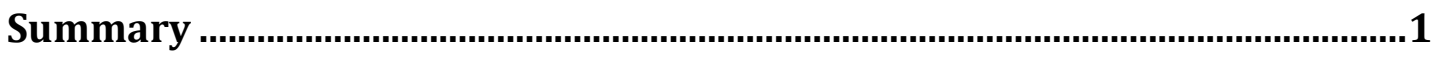

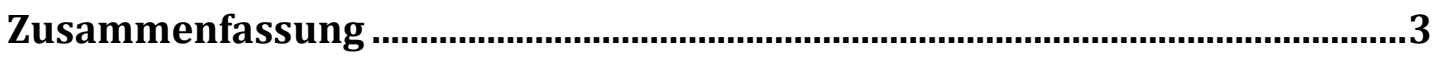

Chapter 1 - General introduction to sex determining mechanisms in Nile

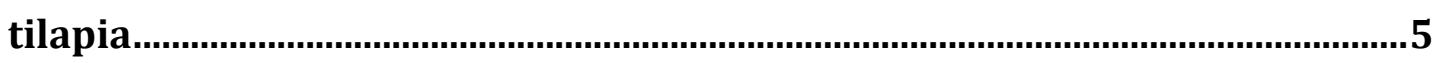

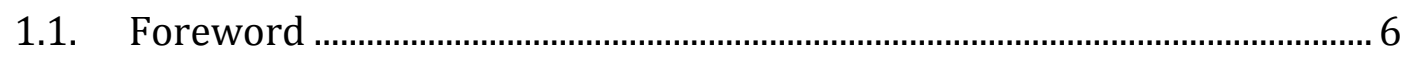

1.2. Sex determination in Nile tilapia - an overview............................................... 6

1.2.1. Major genetic sex-determining factors - sex chromosomes................. 7

1.2.2. Minor genetic sex-determining factors - autosomal factors ............... 7

1.2.3. Environmental sex determination .......................................................... 8

1.3. Sex determination in Nile tilapia - a polygenic system? …………............10

1.3.1. Genetic sex determination.......................................................................10

1.3.2. Temperature-dependent sex ratios ..........................................................11

1.4. Genetic and temperature-dependent factors for sex determination - the ends of a continuum? ………………………………………………………….....13

1.5. Molecular mechanisms of sex determination processes.............................14

1.5.1. Genetic linkage maps for Oreochromis spp............................................14

1.5.2. QTL and marker associations for the phenotypic sex in Oreochromis

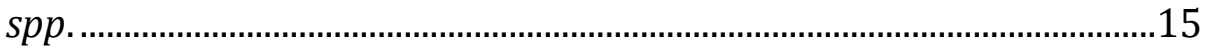

1.5.3. Candidate genes for sex determination...................................................16

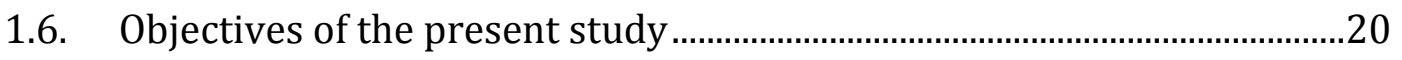

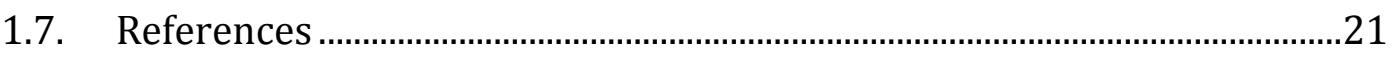


Chapter 2 - Additive, dominance, and reciprocal effects for temperaturedependent sex ratios of Nile tilapia (Oreochromis niloticus) using test cross

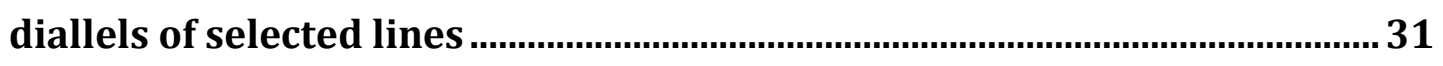

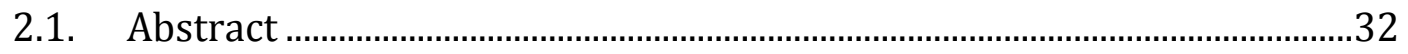

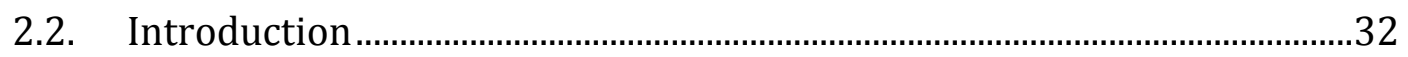

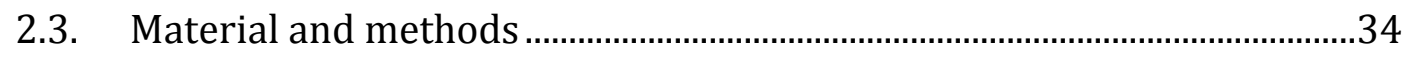

2.3.1. Mating design and temperature treatments ..............................................34

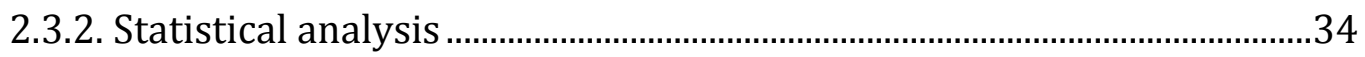

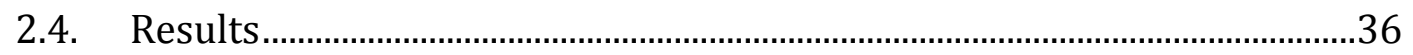

2.4.1. Treatment-dependent sex ratios .....................................................................

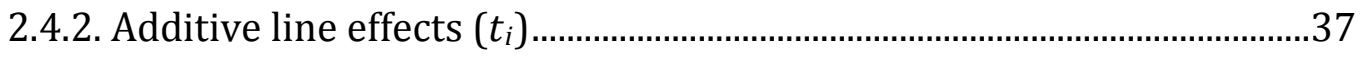

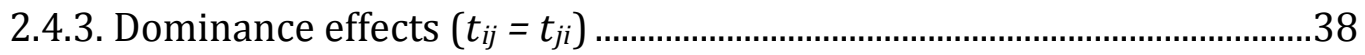

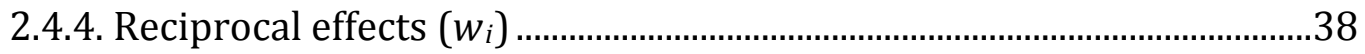

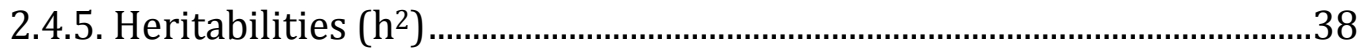

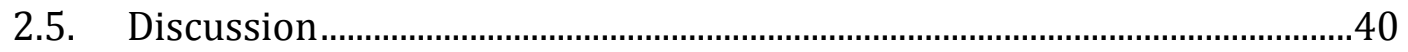

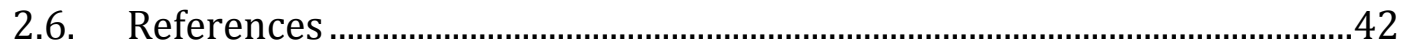

Chapter 3 - First evidence for family-specific QTL for temperaturedependent sex reversal in Nile tilapia (Oreochromis niloticus) .................45

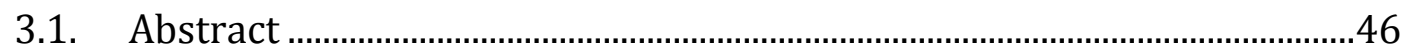

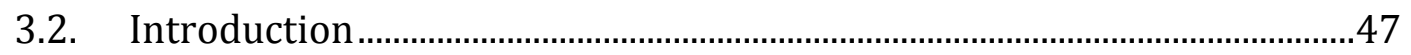

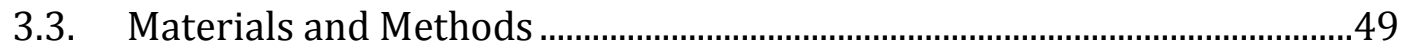

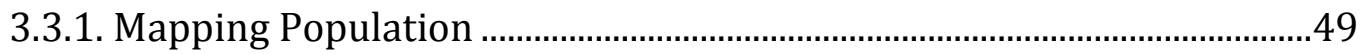

3.3.2. Genotyping of microsatellite markers ......................................................49

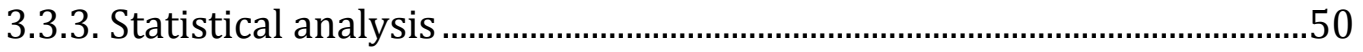

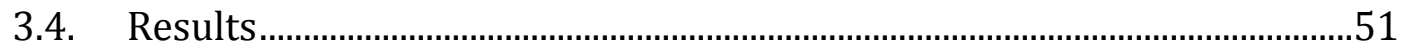

3.4.1. Temperature-dependent phenotypic sex of the mapping population 51

3.4.2. Marker properties .51 
3.4.3. Linkage Map.

3.4.4. Marker trait associations for temperature-dependent phenotypic sex

3.5. Discussion . .58

3.5.1. Phenotyping - temperature-dependent phenotypic sex .58

3.5.2. Marker properties .59

3.5.3. Linkage mapping. .59

3.5.4. Marker trait associations for temperature-dependent phenotypic sex .60

3.6. References .66

Chapter 4 - General Discussion

4.1. Inheritance of sex ratios in 0 . niloticus.........................................................

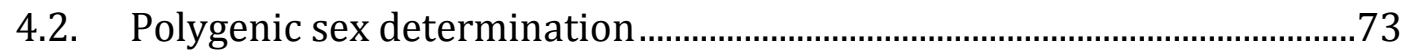

4.3. Interaction of genetic sex determination and temperature effects ........74

4.4. A threshold model for sex determination .....................................................75

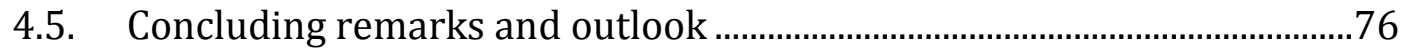

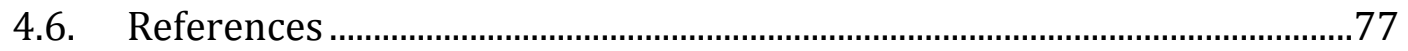

\section{Curriculum vitae}

\section{Acknowledgement - Danksagung}




\section{List of Tables}

Table 1. Current status of linkage maps in Oreochromis spp. (modified from Danzmann and Gharbi, 2007)................................................................................14

Table 2. Male ratios in control and treatment groups in two testcross diallels of the high and low line. 37

Table 3. Maximum-likelihood and odds ratio estimation of the line additive $\left(t_{i}\right)$, line reciprocal $\left(w_{i}\right)$ and dominance effects $\left(t_{i j}\right)$ in the first and second testcross diallel (diallel 1 and diallel 2) of the high and low temperaturesusceptible lines. 39

Table 4. Number of males and females and male ratios in the control $\left(28^{\circ} \mathrm{C}\right)$ and temperature-treated $\left(36^{\circ} \mathrm{C}\right)$ groups of the genetically all-female $\mathrm{F}_{1}$ families. .52

Table 5. Characteristics of the chosen microsatellite markers with positions on the genetic map by Lee et al. (2005) and marker trait association statistics $\left(\chi^{2}, p\right)$ for the temperature-dependent phenotypic sex. .53

Table 6. Population wide QTL statistics for temperature-dependent phenotypic sex in a genetically all-female (XX) population of $O$. niloticus. .55

Table 7. Number of males and females for each genotype of family-specific significantly associated loci with the temperature-dependent sex. .56 


\section{List of Figures}

Figure 1. Illustration of the mapping of the major sex-determining region of Oreochromis niloticus on linkage group 1(red dot), candidate genes for sex determination (green boxes) and genetic markers associated with the phenotypic sex of Oreochromis spp. (highlighted in light blue) on the linkage groups 1, 3, and 23 of the linkage map by Lee et al. (2005). 17

Figure 2. Comparison of the genetic linkage map of Lee et al. (2005) (white) and the combined linkage map of six genetically all-female (XX) temperaturetreated intercross families (blue) of O.niloticus. Marker distances in Kosambi cM are given to the left of each linkage group. .54

Figure 3. QTL statistics for linkage group 1 within family 6 of the intercross mapping population. .57

Figure 4. QTL statistics for linkage group 3a within family 2 of the intercross mapping population.

Figure 5. QTL statistics for linkage group 23 within family 4 of the intercross mapping population. .58 


\section{List of Publications}

Lühmann, L., Knorr, C., Hörstgen-Schwark, G., Wessels, S.: First evidence for family-specific QTL for temperature-dependent sex reversal in Nile tilapia (Oreochromis niloticus)

(manuscript has been accepted for publication in "Sexual Development", 23.04.2012, Manuscript No.: 201201005).

\section{List of Conference Contributions}

Lühmann, L., Samavati, S., Wessels, S., Hörstgen-Schwark, G. (2009): The effect of temperature and hormone treatments during embryonic and post-larvae stages on sex differentiation in Nile tilapia (Oreochromis niloticus). Poster. Book of Abstracts of $10^{\text {th }}$ International Symposium on Genetics in Aquaculture, Bangkok, Thailand, June, 22.-26., 2009, page 217

Lühmann, L., Wessels, S., Hörstgen-Schwark, G. (2010): Detection of nonadditive genetic effects on temperature dependent sex determination in Nile tilapia (Oreochromis niloticus). Poster. Book of Abstracts. Deutscher Tropentag, 14.-16. September 2010, Zürich, Switzerland. p. 462 http://www.tropentag.de/2010/proceedings/proceedings.pdf

Lühmann, L., Knorr, C., Hörstgen-Schwark, G., Wessels, S. (2011): Temperatur trifft Genetik: Molekulargenetische Untersuchungen zum temperaturabhängigen Geschlecht bei Nilbuntbarschen (Oreochromis niloticus). Vortragstagung der DGfZ und GfT am 6./7. September 2011 in FreisingWeihenstephan. A17 


\section{Summary}

Tilapia is one of the most important species group for aquaculture production. Particularly Nile tilapia (Oreochromis niloticus) amounts to over $80 \%$ of the world tilapia production. All-male populations are favourable due to the better growth of the males and for avoiding uncontrolled reproduction. For the production of all-male populations, the application of the androgen 17- $\alpha$ methyltestosterone via the feed is a common practice. The application of masculinising temperatures during early larval stages of 0 . niloticus could substitute the common practice of application of androgens.

The phenotypic sex of 0 . niloticus is a complex trait determined by major and minor genetic factors as well as temperature influence. The complex mechanisms of sex determination in Nile tilapia have not yet been completely understood and the patterns of inheritance as well as the molecular genetic background of sex determination in general and temperature-dependent phenotypic sex in particular are a lively discussed field. The first part of the current study provides first estimates of additive, dominance and reciprocal effects as well as the estimation of narrow sense heritabilities for the temperature-dependent sex ratios of $O$. niloticus using complete testcross diallels of a high and weakly temperature-susceptible line. Estimates of narrow sense heritabilities for the temperature-dependent sex ratios in progeny groups resulted in 0.74 for the high and 0.51 for the weakly sensitive line. A negative dominance effect was found for the weakly sensitive line and a negative reciprocal effect was identified for the low susceptible line as maternal breeder. Maternal effects on the temperature-susceptibility of progeny groups are discussed.

The second part of the study demonstrates a first evidences for family-specific marker trait associations and QTL for the temperature-dependent phenotypic sex in Nile tilapia on linkage groups (LG) 1, 3, and 23. The study screened 21 microsatellites on these LGs for associations with the temperature-dependent sex of Nile tilapia using a temperature-treated genetically all-female (XX) population. Single marker analysis resulted in family-specific associations for UNH995 and UNH104 on LG 1, GM213 on LG 3, and UNH898 and GM283 on 
LG 23. However, no population-wide QTL or marker trait associations could be detected. Further QTL on different linkage groups were suggested and prospects for following studies are discussed.

In previous studies by different authors, several genetic markers on these LGs were proven to be associated with the phenotypic sex of different tilapia species (Oreochromis spp.) and interspecies crosses. Furthermore, putative master key regulators for sex determination in tilapia were mapped to the three LGs. Therefore, the study reveals new information for the coexistence of genetic and temperature effects on the development of the phenotypic sex in Nile tilapia and provides useful information for further research on sex determining processes and for prospective breeding programs for temperature-induced masculinisation in order to substitute hormone treatments in production systems. 


\section{Zusammenfassung}

Tilapien spielen eine erhebliche Rolle in der weltweiten Aquakultur-Produktion. Dabei machen Nilbuntbarsche (Oreochromis niloticus) den größten Teil der weltweiten Tilapien-Produktion aus (> $80 \%$ ).

Bei der Produktion dieser Spezies hat sich der Einsatz von rein-männlichen Populationen stark bewährt. Durch den Einsatz von eingeschlechtlichen Beständen kann eine unkontrollierte Vermehrung während der Produktion vermieden werden. Zudem weisen die männlichen Fische ein stärkeres Wachstum auf. Eine häufig angewendete Methode zur Erstellung solcher rein-männlichen Bestände ist die Verabreichung von Androgenen (17- $\alpha$-Methyltestosteron) über das Futter an die Larven. Diese Technik könnte durch den Einsatz umweltfreundlicher, vermännlichend wirkender Temperaturprotokolle abgelöst werden.

Das phänotypische Geschlecht von O. niloticus ist ein komplexes Merkmal welches durch genetische Haupt- und Nebenfaktoren bestimmt wird. Zudem hat die Wassertemperatur während der juvenilen Phase einen Effekt auf die Ausbildung des phänotypischen Geschlechts. Die vielschichtigen Mechanismen der Geschlechtsdetermination sowie die Vererbungsmechanismen und die molekulargenetischen Hintergründe stellen einen starken Anreiz für wissenschaftliche Untersuchungen dar, konnten jedoch bis jetzt noch nicht vollständig aufgeklärt werden.

Der erste Teil der vorliegenden Studie beschäftigt sich mit der Schätzung von genetischen Parametern bei der Vererbung der temperaturabhängigen Geschlechterverhältnisse. Anhand vollständiger Diallele einer hoch und einer niedrig temperatursensiblen Linie wurden additive Effekte, Dominanzeffekte und reziproke Effekte auf die Vererbung der Temperatursensibilität geschätzt. Weiterhin wurden Heritabilitäten für die temperaturabhängigen Geschlechterverhältnisse für diese divergent selektierten Linien über drei Selektionsgenerationen geschätzt. Hierbei ergaben sich Heritabilitäten von 0.74 für die hoch sensible Linie und von 0.51 für die niedrig sensible Linie. Durch die diallelen Anpaarungen konnte ein negativer Dominanzeffekt der niedrig sensiblen Linie ermittelt werden. Zudem zeigte sich ein negativer reziproker Effekt auf die tempe- 
raturabhängigen Männchenanteile in den Nachkommengruppen bei dem Einsatz von niedrig temperatursensiblen Müttern. Im Zuge dessen werden maternale Effekte auf die Temperatursensibilität der Nachkommen diskutiert.

Der zweite Teil der vorliegenden Untersuchung erbringt einen ersten Beweis für familien-spezifische Merkmals-Marker-Assoziationen sowie QTL für das temperaturabhängige phänotypische Geschlecht von Nilbuntbarschen auf den Kopplungsgruppen (KG) 1, 3 und 23. Insgesamt wurden 21 Mikrosatellitenmarker auf diesen Kopplungsgruppen anhand einer temperaturbehandelten, genetisch rein weiblichen (XX) Population untersucht. Anhand von EinzelmarkerAnalysen konnten familien-spezifische Assoziationen zum temperaturabhängigen Geschlecht für UNH995 und UNH104 auf KG 1, für GM213 auf KG 3 sowie für UNH898 und GM283 auf KG 23 nachgewiesen werden und merkmalsspezifische Allelsegregationen erkannt werden. Es konnte kein Nachweis für familienübergreifende QTL oder Marker-Assoziationen gefunden werden. Es werden Vermutungen über weitere QTL auf anderen als den untersuchten Kopplungsgruppen angestellt.

Unterschiedliche Studien konnten im Vorhinein schon Marker-Assoziationen mit dem phänotypischen Geschlecht verschiedener Tilapienarten (Oreochromis spp.) und interspezifischen Kreuzungen auf diesen Kopplungsgruppen nachweisen. Zudem konnten verschiedene Kandidatengene für die Geschlechtsdetermination diesen drei Kopplungsgruppen zugeordnet werden. Durch den Nachweis von QTL für das temperaturabhängige Geschlecht auf eben diesen Kopplungsgruppen liefert die Untersuchung neue Erkenntnisse über die Koexistenz und den Zusammenhang von genetischen und temperaturabhängigen Effekten auf die Geschlechtsdetermination. Daraus können bedeutende Informationen für weitere Untersuchungen $\mathrm{zu}$ Geschlechtsdeterminationsprozessen abgeleitet werden. Diese Kenntnisse werden besonders für potentielle Zuchtprogramme zur erfolgreichen Maskulinisierung über Temperaturbehandlungen von Bedeutung sein. 


\section{Chapter 1}

General introduction to

sex determining mechanisms

in Nile tilapia 


\subsection{Foreword}

Tilapia represents the second most important species group in aquaculture production. Particularly Nile tilapia (Oreochromis niloticus) accounts for over $80 \%$ of the world tilapia production of 3.1 million tons per year (FAO, 2011). Due to the fast growth, the tolerance for environmental factors and microbiological hazards, a very short generation interval and low feed quality demands, tilapia are a widely spread species in extensive and semi-intensive aquaculture production systems. However, the production of tilapia also poses some challenges. All species of the genus Oreochromis are maternal mouth brooders. During the incubation of eggs and fry, the females stop to feed which results in stunting in the production system and reduced carcass weights of the fish. Therefore, the production of mixed-sex populations is less productive in such production systems. Due to the better growth of males, the production of all-male populations is the method of choice. The most common technique for all-male production, especially in pond systems, is the application of 17- $\alpha$ methyltestosterone (MT) to the swim-up larvae via the feed. This method is barely accepted by the consumers and environmental influences must not be neglected. The application of masculinising temperatures to Oreochromis niloticus constitutes a very promising perspective for the substitution of hormone application in an economically, ecologically and customer friendly way.

\subsection{Sex determination in Nile tilapia - an overview}

The determination of sex in tilapia is a very complex mechanism and it is not yet completely understood. Within the genus Oreochromis both male (XX/XY) and female (ZZ/WZ) heterogametic sex determination systems are described.

The genetic sex determination (GSD) of Nile tilapia is governed by major genetic factors with a male heterogametic system (XX/XY) (Jalabert et al., 1971; Mair et al., 1991). However, minor genetic (autosomal) factors are able to override these factors (Müller-Belecke and Hörstgen-Schwark, 1995). Furthermore, in- 
creased water temperatures during juvenile stages are able to bias the respective sex ratio in favour of males (Baroiller et al., 1995a; b; Tessema et al., 2006).

\subsubsection{Major genetic sex-determining factors - sex chromosomes}

There is a large variety of sex-determining systems in fish (Nakamura et al., 1998). Many species exhibit a genetic sex determining system in the absence of heteromorphic sex chromosomes. In Nile tilapia, no karyotypic heteromorphic sex chromosomes can be found as well (Majumdar and McAndrew, 1986). However, a genetic sex determining system, comparable to the mammalian $\mathrm{XX} / \mathrm{XY}$ system can be assumed for Nile tilapia, suggesting that they represent an early evolutionary stage of sex-chromosomal differentiation (Cnaani et al., 2008; Baroiller et al., 2009b). By the analysis of the synaptonemal complex of meiotic chromosomes, Foresti et al. (1993) found size differences in the terminal region of the largest bivalent. In this bivalent Foresti et al. (1993), later confirmed by Carrasco et al. (1999) identified an incompletely paired segment during the meiotic synapsis process. In addition, Harvey et al. (2002) detected sequence differences in the terminal region of this largest pair of chromosomes. It can be assumed that the largest pair of chromosomes can be defined as the sex chromosomes (X and Y) of O. niloticus (Harvey et al., 2002; Cnaani et al., 2008).

\subsubsection{Minor genetic sex-determining factors - autosomal factors}

Despite the fact that in general a male heterogametic sex determination system exists in Nile tilapia, the simple model of a monofactorial sex determination system was not sufficient to explain all observed sex ratios. Deviations from this system have been observed in investigated sex ratios (Mair et al., 1991). Variations in sex ratios were observed particularly in experiments using genetically all-female $(\mathrm{XX})$ or all-male (XY) populations of 0 . niloticus. Progeny groups of matings between YY-males and XX-females (Mair et al., 1997) or between pseudomales (XX) and normal females (XX) (Calhoun and Shelton, 1983) did not show the expected sex ratios of $100 \%$ males or $100 \%$ females, respectively. 
Moreover, in experiments with meiotic or mitotic gynogenetic progenies of $O$. niloticus, unexpected males occurred (Mair et al., 1991; Müller-Belecke and Hörstgen-Schwark, 1995, Ezaz et al., 2004). Müller-Belecke and HörstgenSchwark (1995) assumed a sex determination system for O. niloticus consisting of major genetic factors $(\mathrm{XX} / \mathrm{XY})$, which can be overridden by two or more minor genetic factors.

\subsubsection{Environmental sex determination}

It has been suggested that sex determination in Oreochromis species is determined by major and minor genetic factors. However, exogenous factors like sex steroid application or water temperature shifts influence the phenotypic sex of tilapia. Such exogenous factors can influence the sex differentiation divergent to the genetically determined sex if applied during the time of undifferentiated gonads (Yamamoto, 1969; D'Cotta et al., 2001). In O. niloticus the critical sensitive period for the environmental sex determination lasts from the $10^{\text {th }}$ until the $19^{\text {th }}$ day post fertilization (dpf). During this time, the gonads are still undifferentiated. The first indicators of differentiation appear as an increase in the number of somatic cells followed by an active mitosis of the primordial germ cells in the gonads (Kwon et al., 2000; D'Cotta et al., 2001). In accordance to the histological studies for the sex differentiation, D'Cotta et al. (2001) found a sex-dimorphic expression of the gene cyp19a, which codes for the enzyme P450aromatase, from the $18^{\text {th }}$ until the $26^{\text {th }} \mathrm{dpf}$. Aromatase catalyses the synthesis of estrogens from androgens and females showed a higher expression of cyp19a in contrast to males just after the stage of sexual lability.

\section{Exogenous steroids}

The first and fundamental studies on the influence of exogenous sex steroids to the phenotypic sex of fish were provided by Yamamoto in 1969. He succeeded in the production of all-male and all-female populations of Oryzia latipes by the application of androgens and estrogenes, respectively. However, the successful production of mono-sex populations strictly depends on the stage of develop- 
ment. A hormone treatment should be applied during the time of sexual lability before the onset of sexual differentiation (Nakamura and Nagahama, 1985). Until now, the mechanisms of exogenous steroid action during the sexual lability are unclear. Bogart (1987) assumed that the sex differentiation depends on the androgen to estrogen ratio. Thereby, the synthesis of androgens triggered by the enzyme P450aromatase plays an essential role. The expression of aromatase (cyp19a gene) has been proven to be suppressed in O. niloticus by the application of 17- $\alpha$-methltestosterone (MT) during the time of the critical sensitive period (Bhandari et al., 2006). Beside that, Kah et al. (1993) assumed a feedback effect of the steroids on the brain-pituitary-gonad axis.

Under practical conditions, the application of androgens has been proven to be a useful tool for the production of all-male tilapia. To obtain the maximal percentage of males ( $\geq 95 \%$ ), hormone treatments should start simultaneously to the first feeding period, because it is congruent with the critical sensitive period for sex determination and treatments should be continued for at least 21 days with a dosage of 30 - 60 mg MT per kg feed (Phelps, 2006).

\section{Temperature-dependent sex determination}

Elevated water temperatures during juvenile stages of $O$. niloticus are able to override the genetic sex and to bias the respective sex ratio in favour of males. Temperatures of more than $34^{\circ} \mathrm{C}$, applied during the juvenile stage, can lead to higher proportions of males (Baroiller et al., 1995a; b). The temperature shift has to be applied during the critical sensitive period, while the gonads are in an undifferentiated stage (v.s.). The most effective temperature treatment starts at the $10^{\text {th }} \mathrm{dpf}$ and lasts for 10 days at $36^{\circ} \mathrm{C}$ (Baroiller et al., 1995a; b; Tessema et al., 2006). At temperatures of $36^{\circ} \mathrm{C}$, the highest rate of males was achieved without influencing the survival rates. Additionally, a treatment of more than 10 days did not increase the male proportion. Thereby, a treatment starting after the $13^{\text {th }}$ dpf was not successful at all (Baroiller et al., 1995a; 1996; Tessema et al., 2006). 


\subsection{Sex determination in Nile tilapia - a polygenic system?}

\subsubsection{Genetic sex determination}

As described before, the genetic sex determination of $O$. niloticus is governed by major and minor genetic factors. Minor genetic factors are able to bias the respective sex ratio in mixed sex populations from a 1:1 distribution. The sex determination of tilapia has been assumed to be a polygenic system (Calhoun and Shelton, 1983; Lester et al., 1989; Tuan, 1999).

Bull (1983) described a polyfactorial system of sex determination as a mechanism, which is controlled by the interaction of many different factors. Three criteria can be assumed to define a polyfactorial sex determination (Bull, 1983):

- a large between-family sex ratio variance,

- paternal and maternal effects on family sex ratio,

- sex ratios response to selection.

For the sex ratios of $O$. niloticus, all criteria are fulfilled.

Large variations in the sex ratios were observed for different families (Calhoun and Shelton, 1983; Lester et al., 1989; Wohlfarth and Wedekind, 1991; Tuan, 1999).

Moreover, the male proportions differ depending on the mating partners. Therefore, maternal and paternal factors have an effect on the genetic sex determination (Tuan, 1999). A response to selection for sex ratios has been suggested by (Wohlfarth and Wedekind, 1991). Heritabilities for sex ratios were estimated by Lester et al. (1989). At normal rearing temperatures, they estimated a heritability $\left(h^{2}\right)$ of 0.26 .

In a considerable experiment, using a complete diallel cross of eight strains of GIFT tilapia (genetically improved farming tilapia), Lozano et al. (2011) estimated strain additive genetic, heterosis and reciprocal effects for male proportions. They solely found the strain heterosis effect to differ significantly from zero. Moreover, the significance could not be reproduced across seven different test environments. They concluded that the heterosis effect may be due to naturally sex-reversed individuals or to an introgression of 0 . mossambicus genes. 
Additionally, influences of different water temperatures, acting on progenies' or parents' sex, were discussed. Therefore, it can be assumed that sex is in general a polygenic trait, since major, minor, and environmental factors interact. However, sex ratios at normal ambient temperatures have a strong genetic background with low influences of family variation and maternal or paternal factors. Such effects may mostly be due to environmental factors, especially to temperature effects, acting on the sex determination system.

\subsubsection{Temperature-dependent sex ratios}

Several studies investigated the dependency of susceptibility to temperature treatments on the population and on the combination of mating partners in O. niloticus. Differences in the susceptibility to temperature treatments were investigated by Tessema et al. (2006) for different populations and population crosses. The authors tested two different populations of 0 . niloticus (Lake Manzala and El Molo). The Lake Manzala population showed a higher responsiveness to the temperature treatment with regard to male ratios compared to the El Molo population. Substantial differences in the temperature susceptibility of progeny groups in the intra-population matings were identified, indicating strong between-family variations. Such interfamiliar variations were also verified by Baroiller et al. (2009a) and Baroiller and D'Cotta (2001). Additionally, maternal and paternal effects on the temperature susceptibility have been confirmed in different studies by single pair matings (Baroiller and Clota, 1998; Baroiller and D'Cotta, 2001; Tessema et al., 2006). Baroiller and D'Cotta (2001) stated that a given couple of mating partners will produce equal sex ratios in temperature treatment for full sibs. However, the sensitivity is strongly dependent on the set of mating partners.

Temperature-dependent sex ratio is a heritable trait and it can be selected for as a quantitative trait. Wessels and Hörstgen-Schwark $(2007 ; 2011)$ succeeded in the selection for high and low temperature-responding lines, described as the high and low line. Within three generations of selection the percentage of males in temperature-treated progeny groups of the high and the low line was more than $92 \%$ and less than $53 \%$, respectively. The cumulated realized heritability 
for the high and low line was 0.63 and 0.84 , respectively, after three generations of selection.

Wessels and Hörstgen-Schwark (2007) and Baroiller and Clota (1998) assumed an additive model of temperature-driven sex ratios in Nile tilapia. This is not only hypothesised for the temperature-dependent phenotypic sex in $O$. niloticus but also for the European sea bass (Dicentrarchus labrax) (Saillant et al., 2002) and the Atlantic Silverside (Menidia menidia) (Conover and Kynard, 1981). Contrary to that, Baroiller and D'Cotta (2001) suggested that only male breeders can sire either all sensitive or all non-sensitive progenies. Furthermore, the first indication for non-additive effects of temperature-dependent sex ratio inheritance in Nile tilapia can be found in the study by Tessema et al. (2006) showing a stronger effect of a low temperature susceptible population on the progenies' phenotypic sex. The average temperature-dependent male ratio of the population crosses was lower than for the purebreds of the low temperature responding El Molo population. In crosses of highly susceptible Lake Manzala males with El Molo females, the authors obtained higher male ratios by temperature treatment than in the reciprocal crosses. Such results are due to parental strain effects showing that a low temperature response of parents may have a stronger influence on the progenies temperature-dependent phenotypic sex. However, the different pathways of inheritance of temperature susceptibility are still unknown.

Temperature-dependent sex ratios of tilapia and European sea bass (Dicentrarchus labrax) as well have been assumed to underlie a polygenic system (Desprez et al., 2006; Vandeputte et al., 2007). Therefore, different genetic loci and genes are involved in the expression of the temperature-dependent phenotypic sex. However, there is no ample knowledge of genetic components contributing to temperature effects on the phenotypic sex in Nile tilapia but it is hypothesized that merely the interaction of genetic factors and temperaturedependent factors will contribute to finally explain the variety of sex ratios (Lee and Kocher, 2007; Cnaani et al., 2008). 


\subsection{Genetic and temperature-dependent factors for sex determi- nation - the ends of a continuum?}

The evolutionary role, the development and the interdependence of genetic and environmental factors influencing sex-determining processes is an ongoing discussion (Sarre et al., 2004; Bull, 2008; Ospina-Alvarez and Piferrer, 2008; Shoemaker and Crews, 2009). It has long been suggested that the phenotypic sex of species with genetic sex determination (GSD) is exclusively determined by genetic factors, which are predominantly independent from the environment. Furthermore, the sex of species with temperature-dependent sex determination (TSD), especially of reptiles, has been assumed to be largely independent of genetic influences, determined after fertilisation by the environment during incubation (Bull, 1983). Therefore, it has been assumed, that TSD and GSD are mutually exclusive and can be seen as two fundamentally different traits (Bull, 1981; Bull, 1985; Valenzuela et al., 2003). Recent studies in reptiles and also in fish lead to the conclusion, that genetic and environmental factors for sex determination interact and display a continuum. Sarre et al. (2004) argued that GSD and TSD in reptiles represent the ends of a continuum and genetic as well as environmental factors co-exist and interact. A similar complexity of the sex determining process can be supposed for tilapia (Baroiller et al., 2009a) because of the presence of both major genetic (sex chromosomal) factors and temperature-dependent factors. Thereby, it has to be considered that Ospina-Alvarez and Piferrer (2008) distinguished between species with real TSD and species with genotypic sex determination plus temperature effect (GSD + TE) in order to discern true cases of TSD. Thus, TSD is defined by occurrence under natural conditions. According to this, sex determination in $O$. niloticus has to be defined as GSD + TE due to the lack of evidence for temperature effects under natural conditions (Baroiller et al., 2009a). For this intermediate case, Grossen et al. (2011) proposed a quantitative model for temperature-dependent turnovers in sex-determining mechanisms concerning the interaction of genetic and temperature effects. They argued that in a quantitative-genetics perspective, sex in general can be seen as a threshold trait that depends on an underlying liability factor which is under both genetic and environmental influence. Therefore, sex determination is neither purely ge- 
netic nor environmental but rather results from an interaction between both factors.

In Nile tilapia, a coexistence of GSD and temperature effects on the phenotypic sex has been postulated (Wessels and Hörstgen-Schwark, 2007). However, it is still questionable whether a genetic correlation between genetic and temperature effects on the phenotypic sex exists and therefore, if loci associated with temperature-dependent sex or GSD reside on the same linkage groups, are located close to each other, or are essentially the same.

\subsection{Molecular mechanisms of sex determination processes}

\subsubsection{Genetic linkage maps for Oreochromis spp.}

Until now, three different genome-wide linkage maps exist for Oreochromis spp. They were built on the basis of purebreds of O. niloticus (Kocher et al., 1998) and interspecies crosses with the O. aureus (Lee et al., 2005) and O. aureus and O. mossambicus (Agresti et al., 2000). Each map was compiled using different types of genetic markers (amplified fragment-length polymorphisms (AFLP), microsatellites (MS), and genes). Table 1 presents an overview over the parameters of the different linkage maps.

Table 1. Current status of linkage maps in Oreochromis spp. (modified from Danzmann and Gharbi, 2007).

\begin{tabular}{|c|c|c|c|c|}
\hline Species & $\begin{array}{l}\text { Mapping } \\
\text { panel }\end{array}$ & $\begin{array}{l}\text { Number of } \\
\text { markers * }\end{array}$ & $\begin{array}{l}\text { Number of } \\
\text { linkage groups }\end{array}$ & Reference \\
\hline O. niloticus & haploids & $\begin{array}{l}112 \text { (AFLP), } \\
62 \text { (MS) }\end{array}$ & 30 & Kocher et al. (1998) \\
\hline $\begin{array}{l}\text { O. niloticus } \mathrm{x} \\
\text { O. aureus } \mathrm{x} \\
\text { O.mossambicus }\end{array}$ & $\begin{array}{l}\text { interspecies } \\
\text { 3-way cross }\end{array}$ & $\begin{array}{l}229 \text { (AFLP), } \\
63 \text { (MS) }\end{array}$ & 24 & Agresti et al. (2000) \\
\hline $\begin{array}{l}\text { O. niloticus } \mathrm{x} \\
\text { O. aureus }\end{array}$ & $\begin{array}{l}\text { interspecies } \\
\mathrm{F}_{2} \text {-cross }\end{array}$ & $\begin{array}{l}525 \text { (MS), } \\
21 \text { (genes) }\end{array}$ & 24 & Lee et al. (2005) \\
\hline
\end{tabular}

* AFLP: amplified fragment-length polymorphism; MS: microsatellite 
Each of the three maps resulted in more than 22 linkage groups (LGs). 22 linkage groups would have been expected because of the number of chromosomes for the Oreochromis spp. The most comprehensive linkage map was generated by Lee et al. (2005) and was recently used in studies dealing with genetic markers. Therefore, it was used as the reference map for following explanations of gene and marker mapping.

\subsubsection{QTL and marker associations for the phenotypic sex in Oreochromis} spp.

Several studies investigated associations of genetic markers with the phenotypic sex of Oreochromis spp. In 2002, Shirak et al. performed the first study by genotyping 222 meiogynogenetic fish of the female heterogametic species (WZ/ZZ) O. aureus for three microsatellite markers (UNH159, UNH216, and UNH231). They found $U N H 216$ and $U N H 231$ to be linked to sex ratio distortion genes. UNH216 has been mapped to LG 23 and UNH231 has been mapped to LG 6 within the linkage map by Lee et al. (2005) (Figure 1). A sex-linked marker on LG 23 (UNH879) was also identified by Cnaani et al. (2003) using a $\mathrm{F}_{2}$-hybrid of O. mossambicus x O. aureus. Later, Lee et al. (2004) assumed that the sex determining locus of 0 . aureus is close to the markers GM354, UNH168, GM271 and UNH131 on LG 3. Additionally, genotypes of LG 1 markers (UNH213 and UNH868) also showed differences between males and females. This locus corresponded to the sex-linked loci GM201, UNH994, and UNH104 found in O. niloticus by Lee et al. (2003). In a $\mathrm{F}_{2}$-hybrid of $O$. niloticus $x$ O. aureus, Lee et al. (2005) found significant linkage of the phenotype exclusively to the microsatellite markers GM354, GM204, UNH168, GM271, GM139, and UNH131 on LG 3 (Figure 1). For O. niloticus, Lee et al. (2003) identified sex linked loci on LG 1 in a $10 \mathrm{cM}$ region between GM201 and UNH104, as mentioned before. Lee and Kocher (2007) narrowed the interval by $6 \mathrm{cM}$, flanked by $w t 1 b$ and UNH995. Lee et al. (2003) suggested a major sex-determining locus to be located within a few cM of UNH995 and UNH104. This suggestion was approved later by Cnaani et al. (2008). Additionally, they physically mapped these sex-linked markers to a small chromosome. 
Recently, Eshel et al. (2011) described a strong association of the microsatellite UNH898 on LG 23 with the phenotypic sex in mixed sex populations of O. niloticus by fine mapping of LG 23 (Figure 1).

\subsubsection{Candidate genes for sex determination}

In mammals, SRY (sex determining region of $\mathrm{Y}$ ) can be seen as the only testis determining factor (Sinclair et al., 1990). In fish and other lower vertebrates, no such gene for the initial sex determination process is certainly known to be conserved (Devlin et al., 1991; Devlin and Nagahama, 2002). The specification of the phenotypic sex is underlying a much more labile system, which can be influenced by environmental factors, such as temperature. Endogenous steroids influencing the sex determination pathway can be excluded because steroidproducing cells occur just after the differentiation of the gonads (Nakamura et al., 1998). Therefore, it can be suggested, that the expression of interacting genes, which are involved in the sex determination and differentiation processes is influenced by the water temperature. Therefore, it can be suggested that temperature-driven phenotypic sex has a strong genetic background.

Putative master key regulators and candidate genes for sex determination in fish are sex determining genes of mammals. Some homologues genes were found in different lower vertebrates and for some of them, sex dimorphic expression patterns have been observed in tilapia (Guiguen et al., 1999; Kwon et al., 2001, Ijiri et al., 2008; Poonlaphdecha et al., 2011). Partially, they have been mapped to the putative sex chromosomes of Oreochromis spp. (Lee et al., 2005; Shirak et al., 2006; Lee and Kocher, 2007; Cnaani et al., 2008). 

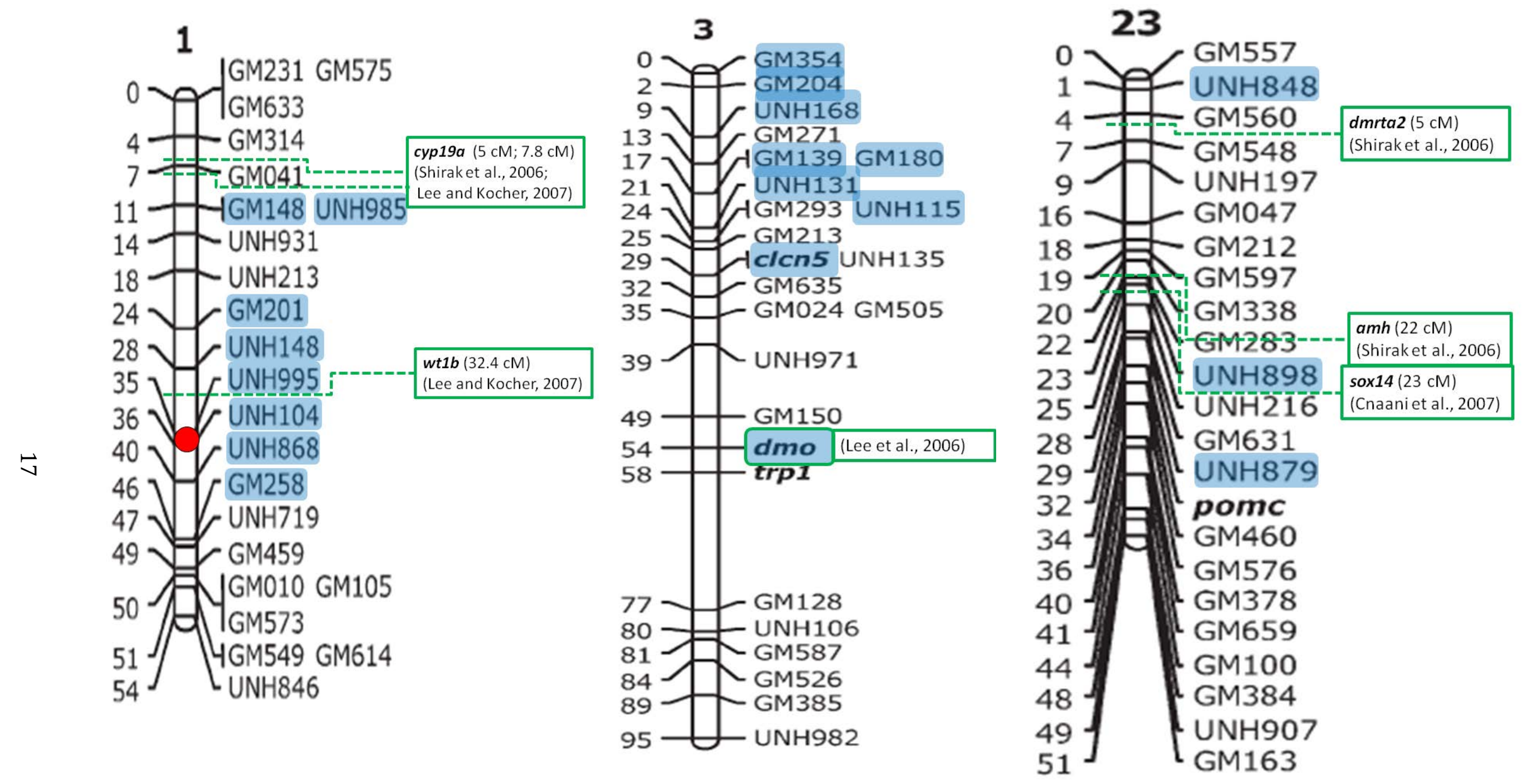

Figure 1. Illustration of the mapping of the major sex-determining region of Oreochromis niloticus on linkage group 1(red dot), candidate genes for sex determination (green boxes) and genetic markers associated with the phenotypic sex of Oreochromis spp. (highlighted in light blue) on the linkage groups 1, 3, and 23 of the linkage map by Lee et al. (2005). 


\section{Cyp 19a}

Cyp19a (cytochrome P450, family 19, subfamily A) is involved in the onset of female sex differentiation of $O$. niloticus by catalyzing the conversion of androgens to $17 \beta$-estradiol. Females showed a higher expression of cyp19a just after the stage of sexual lability (Guiguen et al., 1999; D'Cotta et al., 2001; Kwon et al., 2001; Ijiri et al., 2008). Bogart (1987) hypothesized the suppression of aromatase by a Y-chromosomal gene for species with a male heterogametic system. However a decrease in aromatase expression has also been found in hormonally (Bhandari et al., 2006) and thermally (D'Cotta et al., 2001) sex-reversed XXmales before the onset of ovarian differentiation. Moreover, the application of aromatase inhibitors leads to an increase of males as well (Kwon et al., 2000; Afonso et al., 2001). It has been assumed that environmental effects act on the cyp19a expression either directly or by a genetic cascade (Bhandari et al., 2006; D'Cotta et al., 2001). The expression of cyp19a strongly depends on the expression of the genes amh (Pieau, 1996) and foxl2 (Wang et al., 2007). This correlation supports the hypothesis of a genetic cascade that involves cyp19a. Shirak et al. (2006) and Lee and Kocher (2007) mapped cyp19a to LG 1 between the microsatellites GM633 and UNH985 (Figure 1).

\section{Amh}

The $a m h$ gene (anti-müllerian hormone gene) inhibits the development of the müllerian ducts into ovaries. In tilapia, $a m h$ is known to be expressed earlier in the gonads of XY-males than of XX-females (D'Cotta et al., 2007; Ijiri et al., 2008). Additionally, Poonlaphdecha et al. (2011) provided evidence for a strong sexdimorphic expression of amh in the brain of 0 . niloticus at $14 \mathrm{dpf}$, before the initial start of gonadal differentiation and while gonadal amh expression was not dimorphic. Amh has been mapped next to UNH898 (1 cM distance) on LG 23 (Shirak et al., 2006) (Figure 1). For tilapia, there is no definite proof, for a temperature-dependent expression of amh (D'Cotta et al., 2007). Within other species, the role of $a m h$ in TSD is a controversial issue. Amh is involved in the regulation of cyp19a expression (di Clemente et al., 1992; Josso et al., 1998). A temperature-related expression of amh could be the result of a negative feedback effect of cyp19a expression (Pieau, 1996). 


\section{Foxl2}

The forkhead transcription factor gene foxl2 (forkhead box L2) is involved in the early ovarian development and differentiation and is highly conserved in different species (Cocquet et al., 2003; Loffler et al., 2003; Baron et al., 2004). In $O$. niloticus, foxl2 showed higher expression levels in gonads of $\mathrm{XX}$-animals from the $5^{\text {th }}$ day after hatching (dah), increasing until the $35^{\text {th }}$ dah. Expression levels of foxl2 in XY-gonads remained consistently low (Ijiri et al., 2008). FoxL2 has been mapped to $17 \mathrm{cM}$ on LG 14 (Shirak et al., 2006). Concerning tilapia, there is no definite proof, that the expression of foxl2 is temperature-dependent.

However, Shoemaker et al. (2007) provided evidence that foxl2 is involved in the sex determination of the red-eared slider turtle (Trachemys scripta), a species with TSD. Foxl2 is involved in the regulation of cyp19a expression as well and a temperature-related expression of foxl2 could also be the result of a negative feedback effect of cyp19a expression (Pieau, 1996).

\section{Wt1}

The wilm's tumor gene (WT1) plays a critical role in mammalian gonadal development (Hossain and Saunders, 2001). Therefore, it is a putative key regulator for sex determination in other vertebrates. In 0 . niloticus, the $w t 1 b$ gene has been mapped to LG 1 (32.4 cM) (Figure 1), flanked by the markers GM201 and UNH995 (Lee and Kocher, 2007). This is the chromosomal region, where the major sex determiner for O. niloticus has been mapped to (Lee et al., 2003; Lee and Kocher, 2007), but it has been excluded as the major sex determining gene (Lee and Kocher, 2007).

\section{Sox-gene family}

The SOX (SRY-related HMG box) gene family consists of 20 different genes in mammals and plays an essential role in sex determination. Many orthologues sox genes have been found in different fish species and some of them in Oreochromis spp. Sox2 has been mapped to LG 17 close to the microsatellite UNH991 and sox14 has been mapped to LG 23 between the markers UNH898 and UNH216 (Figure 1), just $1 \mathrm{cM}$ away from amh (Cnaani et al., 2007). However, only for sox9, sexual dimorphic expressions with higher expressions in $\mathrm{XY}$ - 
gonads of 0 . niloticus have been detected until now (Ijiri et al., 2008; D'Cotta et al., 2007). Sox9 expression is temperature-dependent in different TSD-species (Western et al., 1999; Moreno-Mendoza et al., 2001; Shoemaker et al., 2007). D'Cotta et al. (2007) provided a first evidence for temperature-dependent expression of sox 9 in 0 . niloticus with an earlier increase in XX-gonads compared to XY-gonads.

\section{Dmrt1, dmrta2 and dmo}

Dmrt1 (doublesex and mab-3-related transcription factor 1) and dmrta2 (doublesex- and mab-3-related transcription factor A2) belong to the family of doublesex/mab-3 domain genes. Ijiri et al. (2008) found an early male-specific expression of $d m r t 1$ in gonads of 0 . niloticus, six days after hatching, increasing until day 10 after hatching. Also for medaka (Oryzias latipes), the closely related gene dmy is known to be male specific (Nanda et al., 2002). Additionally, dmrt1 expression is up-regulated by male-producing temperatures in different TSDspecies (Kettlewell et al., 2000; Torres Maldonado et al., 2002; Hattori et al., 2007) but no respective information is available for tilapia. In Oreochromis spp., dmrt1 has been mapped to 44 cM on LG 12 (Lee et al., 2005). Shirak et al. (2006) proposed dmrta2 to be a master key regulator for sex determination in tilapia. They mapped dmrta2 to $5 \mathrm{cM}$ on LG 23 (Figure 1). Additionally, the gene $d m o$ is involved in the gonadal development of the ovaries (Guan et al., 2000) and has been mapped to the region between GM150 and UNH106 on LG 3 (Lee et al., 2005) (Figure 1). Dmo in Nile tilapia represented a novel gene, whose expression was limited to the ovaries (Guan et al., 2000).

\subsection{Objectives of the present study}

The present study deals with quantitative and molecular genetic backgrounds for the temperature-dependent phenotypic sex of Nile tilapia. The first part of the study is targeted on estimating components of inheritance for temperaturedependent sex ratios using complete testcross diallels for high and weakly temperature-susceptible lines of 0 . niloticus. First estimates for additive, dominance 
and reciprocal effects as well as heritability values shall illuminate the different pathways for inheritance of the temperature-dependent phenotypic sex of $O$. niloticus.

The second part of the current study attempts for the first time to find markertrait associations and QTL for the temperature-dependent phenotypic sex in $O$. niloticus using similar line crosses as in the first part. The aim of the QTL study is to extent the knowledge of molecular genetic components contributing to temperature effects on the phenotypic sex in Nile tilapia and to explain the correlation between GSD and temperature effects on the phenotypic sex. Therefore, the study is targeted to screen genetic markers on three linkage groups which have previously been described to be linked to the phenotypic sex of Oreochromis spp. at normal rearing temperatures.

Overall, this study investigates the genetic background of temperature-driven sex determination. Results of this study consider helpful tools for further selection and QTL-studies which could be applied to prospective breeding programs.

\subsection{References}

Afonso, L.O., Wassermann, G.J., Terezinha de Oliveira, R. (2001): Sex reversal in Nile tilapia (Oreochromis niloticus) using a nonsteroidal aromatase inhibitor. The Journal of Experimental Zoology, 290, 177-181.

Agresti, J.J., Seki, S., Cnaani, A., Hulata, G., Gall, G.A.E., May, B. (2000): Breeding new strains of tilapia: development of an artificial center of origin and linkage map based on AFLP and microsatellite loci. Aquaculture, 185, 43-56.

Baroiller, J.F. and Clota, F. (1998): Interactions between temperature effects and genotype on Oreochromis niloticus sex determination. Journal of Experimental Zoology, 281, 507 (abstract).

Baroiller, J.F., and D'Cotta, H. (2001): Environment and sex determination in farmed fish. Comparative Biochemistry and Physiology, 130, 399-409.

Baroiller, J.F., Chourrout, D., Fostier, A., Jalabert, B. (1995a): Temperature and sex-chromosomes govern sex ratios of the mouthbrooding cichlid fish Oreochromis niloticus. Journal of Experimental Zoology, 273, 216-223. 
Baroiller, J.F., Clota, F., Geraz, E. (1995b): Temperature sex determination in two tilapia Oreochromis niloticus and the red tilapia (Red florida strain): Effect of high or low temperature, in Goetz FW, Thomas P (eds): Proceedings of the fifth international symposium on the reproductive physiology of fish. Texas Austin Texas USA July 2-8.

Baroiller, J.F., Fostier, A., Cauty, C., Rognon, X. Jalabert, B. (1996): Effects of high rearing temperatures on the sex ratio of progeny from sex reversed males of Oreochromis niloticus. In: R.S.V. Pullin, J. Lazard, M. Legendre, J.B. Amon Kothias and D. Paul (eds.). The third international symposium an tilapia in aquaculture. ICLARM Conf. Proc. 41, pp. 246-256.

Baroiller, J.F., D’Cotta, H., Bezault, E., Wessels, S., Hörstgen-Schwark, G. (2009): Tilapia sex determination: Where temperature and genetics meet. Comparative Biochemistry and Physiology, 153, 30-38.

Baroiller, J.F., D’Cotta, H., Saillant, E (2009): Environmental effects on fish sex determination and differentiation. Sexual Development, 3, 118-135.

Baron, D., Cocquet, J., Xia, X., Fellous, M., Guiguen, Y., Veitia, R. A. (2004): An evolutionary and functional analysis of FoxL2 in rainbow trout gonad differentiation. Journal of Molecular Endocrinology, 33, 705-715.

Bhandari, R.K., Nakamura, M., Kobayashi, T., Nagahama, Y. (2006): Suppression of steroidogenic enzyme expression during androgen-induced sex reversal in Nile tilapia (Oreochromis niloticus). General and Comparative Endocrinology, 145, 20-24.

Bogart, M.H. (1987): Sex determination: A hypothesis based on steroid ratios. Journal of Theoretical Biology, 128, 349-357.

Bull, J.J. (1981): Of environmental sex determination from genotypic sex determination. Evolution, 47, 173-184.

Bull, J.J. (1983): Evolution of sex determining mechanisms. Benjamin/Cummings, Menlo Park, California, USA. First Edition. ISBN 0805304002 .

Bull, J.J. (1985): Sex Ratio and Nest Temperature in Turtles: Comparing Field and Laboratory Data. Ecology, 66, 1115-1122. 
Bull, J.J. (2008): Sex determination: are two mechanisms better than one? Journal of Biosciences, 33, 5-8.

Calhoun, W. and Shelton, W. (1983): Sex ratios of progeny from mass spawnings of sex-reversed broodstock of Tilapia nilotica. Aquaculture, 33, 365-371.

Carrasco, L.A.P., Penman, D.J., Bromage, N. (1999): Evidence for the presence of sex chromosomes in the Nile tilapia (Oreochromis niloticus) from synaptonemal complex analysis of XX, XY and YY genotypes. Aquaculture, $173,207-218$.

di Clemente, N, Ghaffari, S., Pepinsky, R., Pieau, C, Josso, N, Cate, R., and Vigier, B. (1992): A quantitative and interspecific test for biological activity of antimullerian hormone: the fetal ovary aromatase assay. Development, 114, 721-727.

Cnaani, A., Hallerman, E. M., Ron, M., Weller, J.I., Indelman, M., Kashi, Y., Gall, G.A.E., and Hulata, G. (2003): Detection of a chromosomal region with two quantitative trait loci, affecting cold tolerance and fish size, in an F2 tilapia hybrid. Aquaculture, 223, 117-128.

Cnaani, A, Lee, B-Y, Ozouf-Costaz, C., Bonillo, C., Baroiller, J.F., D’Cotta, H., Kocher, T. (2007): Mapping of sox2 and sox14 in tilapia (Oreochromis spp.). Sexual Development, 1, 207-210.

Cnaani, A, Lee, B-Y, Zilberman, N., Ozouf-Costaz, C., Hulata, G., Ron, M., D’Hont, A., Baroiller, J.F., D'Cotta, H., Penman, D.J., Tomasino, E., Coutanceau, J.-P., Pepey, E., Shirak, A., Kocher, T.D. (2008): Genetics of sex determination in tilapiine species. Sexual Development, 2, 43-54.

Cocquet, J., de Baere, E., Gareil, M., Pannetier, M., Xia, X., Fellous, M., Veitia, R. A. (2003): Structure, evolution and expression of the FOXL2 transcription unit. Cytogenetic and Genome Research, 101, 206-211.

Conover, D. O. and Kynard, B. E. (1981): Environmental sex determination: interaction of temperature and genotype in a fish. Science, $213,577-579$.

Danzmann, R.G. and Gharbi, K. (2007): Linkage Mapping in Aquaculture Species. In: Liu, Z. (ed.): Aquaculture Genome Technologies. Blackwell Publishing, Oxford, UK, First Edition. ISBN 0813802032, pp. 139-167. 
D’Cotta, H., Fostier, A., Guiguen, Y., Govoroun, M., Baroiller, J.F. (2001): Aromatase plays a key role during normal and temperature-induced sex differentiation of tilapia Oreochromis niloticus. Molecular Reproduction and Development, 59, 265-276.

D’Cotta, H., Pepey, E., Pfennig, F., Bienvenu, D., Gutzeit, H.O., Volff, J.N., Wenning, M., Baroiller, J.F. (2007): Sox9a, Sox9b and Amh are up-regulated in the gonads during natural and temperature-induced tilapia male differentiation. In: Proceedings of the 8th International Symposium on Reproductive Physiology of Fish, June 3rd-8th, Saint-Malo, France.

Desprez, D., Briand, C., Hoareau, M., Melard, C., Bosc, P., and Baroiller, J. F. (2006): Study of sex ratio in progeny of a complex Oreochromis hybrid, the Florida red tilapia. Aquaculture, 251, 231-237.

Devlin, R.H., McNeil, B.K., Groves, T.D.D., Donaldson, E.M. (1991): Isolation of a Y-Chromosomal DNA Probe Capable of Determining Genetic Sex in Chinook Salmon (Oncorhynchus tshawytscha). Canadian Journal of Fisheries and Aquatic Sciences, 48, 1606-1612.

Devlin, R., and Nagahama, Y. (2002): Sex determination and sex differentiation in fish: an overview of genetic, physiological, and environmental influences. Aquaculture, 208, 191-364.

Eshel, O., Shirak, A., Weller, J.I., Slossman, T., Hulata, G., Cnaani, A., Ron, M. (2011): Fine-mapping of a locus on linkage group 23 for sex determination in Nile tilapia (Oreochromis niloticus). Animal Genetics, 42, 222-224.

Ezaz, M.T., Myers, J.M., Powell, S.F., Mc Andrew, B.J., Penman, D.J. (2004): Sex ratios in the progeny of androgenetic and gynogenetic YY male Nile tilapia, Oreochromis niloticus L . Conservation Biology, 232, 205-214.

FAO Fisheries Department (2011): Fishery, Information, Data and Statistics Unit. FISHSTAT Plus: Universal Software for fishery statistical time series, Version 2.3.2000.

Foresti, F., Oliveira, C., Galetti, P.M., and de Almeida-Toledo, L.F. (1993): Synaptonemal complex analysis in spermatocytes of tilapia, Oreochromis niloticus (Pisces, Cichlidae). Genome, 36, 1124-1128. 
Grossen, C., Neuenschwander, S., Perrin, N. (2011): Temperature-dependent turnovers in sex-determination mechanisms: a quantitative model. Evolution, 65, 64-78.

Guan, G., Kobayashi, T., Nagahama, Y., (2000): Sexually dimorphic expression of two types of DM (Doublesex/Mab-3)-domain genes in a teleost fish, the Tilapia (Oreochromis niloticus). Biochemical and Biophysical Research Communications, 272, 662-666.

Guiguen, Y., Baroiller, J.F., Ricordel, M. J., Iseki, K., McMeel, O., Martin, S., Fostier, A. (1999): Involvement of estrogens in the process of sex differentiation in two fish species: the rainbow trout (Oncorhynchus mykiss) and a tilapia (Oreochromis niloticus). Molecular Reproduction and Development, 54, 154-162.

Harvey, S.C., Masabanda, J., Carrasco, L.A.P., Bromage, N.R., Penman, D.J., Griffin, D.K. (2002): Molecular-cytogenetic analysis reveals sequence differences between the sex chromosomes of Oreochromis niloticus: evidence for an early stage of sex-chromosome differentiation. Cytogenetic and Genome research, 97, 76-80.

Hattori, R.S., Gould, R.J., Fujioka, T., Saito, T., Kurita, J., Strüssmann, C.A., Yokota, M., Watanabe, S. (2007): Temperature-dependent sex determination in HdrR medaka Oryzias latipes: gender sensitivity, thermal threshold, critical period, and DMRT1 expression profile. Sexual Development, 1, 138-146.

Hossain, A. and Saunders, G. F. (2001): The human sex-determining gene SRY is a direct target of WT1. The Journal of Biological Chemistry, 276, 1681716823.

Ijiri, S., Kaneko, H., Kobayashi, T., Wang, D.-S., Sakai, F., Paul-Prasanth, B., Nakamura, M., Nagahama, Y. (2008): Sexual dimorphic expression of genes in gonads during early differentiation of a teleost fish, the Nile tilapia Oreochromis niloticus. Biology of Reproduction, 78, 333-341.

Jalabert, B., Kammacher, P., Lessent, P. (1971): Déterminisme du sexe chez les hybrides entre tilapia macrochir et tilapia nilotica. étude de la sex-ratio dans les recroisements des hybrides de premiere génération par les espèces parentes. Annales de Biologie Animale Biochemie Biophysique, 11, 155-165. 
Josso, N., Racine, C., di Clemente, N., Xavier, F. (1998): The role of anti-Müllerian hormone in gonadal development. Molecular and Cellular Endocrinology, $145,3-7$.

Kah, O., Anglade, I., Leprêtre, E., Dubourg, P., Monbrison, D. (1993): The reproductive brain in fish. Fish Physiology and Biochemistry, 11, 85-98.

Kettlewell, J.R., Raymond, C.S., Zarkower, D. (2000): Temperature-dependent expression of turtle Dmrt1 prior to sexual differentiation. Genesis, 26, 174178.

Kocher, T.D., Lee, W.J., Sobolewska, H., Penman, D., McAndrew, B. (1998): A genetic linkage map of a cichlid fish, the tilapia (Oreochromis niloticus). Genetics, 148, 1225-3122.

Kwon, J.Y., Haghpanah, V., Kogson-Hurtado, L.M., McAndrew, B.J., Penman, D.J. (2000): Masculinization of genetic female Nile tilapia (Oreochromis niloticus) by dietary administration of an aromatase inhibitor during sexual differentiation. The Journal of Experimental Zoology, 287, 46-53.

Kwon, J.Y., McAndrew, B.J., Penman, D.J. (2001): Cloning of brain aromatase gene and expression of brain and ovarian aromatase genes during sexual differentiation in genetic male and female Nile tilapia Oreochromis niloticus. Molecular Reproduction and Development, 59, 359-370.

Lee, B.-Y. and Kocher, T.D. (2007): Exclusion of Wilms tumour (WT1b) and ovarian cytochrome P450 aromatase (CYP19A1) as candidates for sex determination genes in Nile tilapia (Oreochromis niloticus). Animal genetics, 38, 8586.

Lee, B.-Y., Penman, D.J., Kocher, T.D. (2003): Identification of a sex-determining region in Nile tilapia (Oreochromis niloticus) using bulked segregant analysis. Animal Genetics, 34, 379-383.

Lee, B.-Y., Hulata, G., Kocher, T.D. (2004): Two unlinked loci controlling the sex of blue tilapia (Oreochromis aureus). Heredity, 92, 543-549.

Lee, B.-Y., Lee, W.-J., Streelman, J.T., Carleton, K.L., Howe, A.E, Hulata, G., Slettan, A., Stern, J.E., Terai, Y., Kocher, T.D. (2005): A second-generation genetic linkage map of tilapia (Oreochromis spp.). Genetics, 170, 237-244. 
Lester, L., Lawson, K., Abella, T., Palada, M. (1989): Estimated heritability of sex ratio and sexual dimorphism in tilapia. Aquaculture Research, 20, 369-380.

Loffler, K.A., Zarkower, D., Koopman, P. (2003): Etiology of ovarian failure in blepharophimosis ptosis epicanthus inversus syndrome: FOXL2 is a conserved, early-acting gene in vertebrate ovarian development. Endocrinology, 144, 3237-3243.

Lozano, C., Gjerde, B., Bentsen, H. B., Dionisio, E. E., Rye, M. (2011): Estimates of strain additive genetic, heterosis and reciprocal effects for male proportion in Nile tilapia, Oreochromis niloticus L. Aquaculture, 312, 32-42.

Mair, G.C., Scott, A.G., Penman, DJ, Beardmore, J.A., Skibinski, D.O.E. (1991). Sex determination in the genus Oreochromis 1. Sex reversal, gynogenesis and triploidy in O. niloticus (L.). Theoretical and Applied Genetics, 82, 144-152.

Mair, G.C., Abucay, J.S., Skibinski, D.O.F., Abella, T.A. (1997): Genetic manipulation of sex ratio for the large-scale production of all- male tilapia Oreochromis niloticus L. Canadian Journal of Fisheries and Aquatic Sciences, 54, 396-404.

Majumdar, K.C. and McAndrew, B.J. (1986): Relative DNA content of somatic nuclei and chromosomal studies in three genera: Tilapia, Sarotherodon, and Oreochromis of the tribe Tilapiini (Pisces, Cichlidae). Genetica, 68, 175-188.

Moreno-Mendoza, N., Harley, V.R., Merchant-Larios, H. (2001): Temperature regulates SOX9 expression in cultured gonads of Lepidochelys olivacea, a species with temperature sex determination. Developmental Biology, 229, 319-326.

Müller-Belecke, A. and Hörstgen-Schwark, G. (1995): Sex determination in tilapia (Oreochromis niloticus) sex ratios in homozygous gynogenetic progeny and their offspring. Aquaculture, 137, 57-65.

Nakamura, M. and Nagahama, Y. (1985): Steroid Producing Cells during Ovarian Differentiation of the Tilapia (Sarotherodon niloticus). Development, Growth and Differentiation, 27, 701-708.

Nakamura, M., Kobayashi, T., Chang, X.-T., Nagahama, Y. (1998): Gonadal sex differentiation in teleost fish. Journal of Experimental Zoology, 281, 362372 . 
Nanda, I., Kondo, M., Hornung, U., Asakawa, S., Winkler, C., Shimizu, A., Shan, Z., Haaf, T., Shimizu, N., Shima, A. (2002): A duplicated copy of DMRT1 in the sex-determining region of the $\mathrm{Y}$ chromosome of the medaka, Oryzias latipes. Proceedings of the National Academy of Sciences of the United States of America, 99, 11778-11783.

Ospina-Alvarez, N. and Piferrer, F. (2008): Temperature-dependent sex determination in fish revisited: prevalence, a single sex ratio response pattern, and possible effects of climate change. PloS one, 3, e2837.

Phelps, R.P. (2006): Hormone manipulation of sex. In: Lim, C.E. \&Webster, C.D. (eds.). Tilapia: Biology, Culture and Nutrition. Haworth Press, Binghamton, New York, First Edition, ISBN 1560228881, pp. 211-252.

Pieau, C. (1996): Temperature variation and sex determination in reptiles. BioEssays, 18, 19-26.

Poonlaphdecha, S., Pepey, E., Huang, S.-H., Canonne, M., Soler, L., Mortaji, S., Morand, S., Pfennig, F., Mélard, C., Baroiller, J.F. (2011): Elevated amh gene expression in the brain of male tilapia (Oreochromis niloticus) during testis differentiation. Sexual Development, 5, 33-47.

Saillant, E., Fostier, A., Haffray, P., Menu, B., Thimonier, J., Chatain, B. (2002): Temperature Effects and Genotype-Temperature Interactions on Sex Determination in the European Sea Bass (Dicentrarchus labrax L.). Journal of Experimental Zoology, 292, 494-505.

Sarre, S.D., Georges, A., and Quinn, A. (2004): The ends of a continuum: genetic and temperature-dependent sex determination in reptiles. BioEssays, 26, 639-645.

Shirak, A, Palti, Y., Cnaani, A., Korol, A., Hulata, G., Ron, M., Avtalion, R.R. (2002): Alleles and Distorted Sex Ratios in an Inbred Line of Tilapia (Oreochromis aureus). Journal of Heredity, 97, 270-276.

Shirak, A., Seroussi, E., Cnaani, A., Howe, A.E., Domokhovsky, R., Zilberman, N., Kocher, T.D., Hulata, G., Ron, M. (2006): Amh and Dmrta2 genes map to tilapia (Oreochromis spp.) linkage group 23 within quantitative trait locus regions for sex determination. Genetics, 174, 1573-1581. 
Shoemaker, C.M. and Crews, D. (2009): Analyzing the coordinated gene network underlying temperature-dependent sex determination in reptiles. Seminars in Cell and Developmental Diology, 20, 293-303.

Shoemaker, C.M., Queen, J., and Crews, D. (2007): Response of candidate sexdetermining genes to changes in temperature reveals their involvement in the molecular network underlying temperature-dependent sex determination. Molecular Endocrinology, 21, 2750-2763.

Sinclair, A.H., Berta, P., Palmer, M.S., Hawkins, J.R., Griffiths, B.L., Smith, M.J., Foster, J.W., Frischauf, A.M., Lovell-Badge, R., Goodfellow, P.N. (1990): A gene from the human sex-determining region encodes a protein with homology to a conserved DNA-binding motif. Nature, 346, 240-244.

Tessema, M., Müller-Belecke, A., Hörstgen-Schwark, G. (2006): Effect of rearing temperatures on the sex ratios of Oreochromis niloticus populations. Aquaculture, 258, 270-277.

Torres Maldonado, L.C., Landa Piedra, A., Moreno Mendoza, N., Marmolejo Valencia, A., Meza Martínez, A., Merchant Larios, H. (2002): Expression profiles of Dax1, Dmrt1, and Sox9 during temperature sex determination in gonads of the sea turtle Lepidochelys olivacea. General and Comparative Endocrinology, 129, 20-26.

Tuan, P. (1999): Sex determination and the feasibility of genetically male tilapia production in the Thai-Chitralada strain of Oreochromis niloticus (L.). Aquaculture, 173, 257-269.

Valenzuela, N., Adams, D.C., and Janzen, F.J. (2003): Pattern does not equal process: exactly when is sex environmentally determined? The American Naturalist, 161, 676-683.

Vandeputte, M., Dupont-Nivet, M., Chavanne, H., and Chatain, B. (2007): A polygenic hypothesis for sex determination in the European sea bass Dicentrarchus labrax. Genetics, 176, 1049-1057.

Wang, D.-S., Kobayashi, T., Zhou, L.-Y., Paul-Prasanth, B., Ijiri, S., Sakai, F., Okubo, K., Morohashi, K., Nagahama, Y. (2007): Foxl2 up-regulates aromatase gene transcription in a female-specific manner by binding to the promoter as well as interacting with ad4 binding protein/steroidogenic factor 1 . Molecular Endocrinology, 21, 712-725. 
Wessels, S. and Hörstgen-Schwark, G. (2007): Selection experiments to increase the proportion of males in Nile tilapia (Oreochromis niloticus) by means of temperature treatment. Aquaculture, 272, S80-S87.

Wessels, S. and Hörstgen-Schwark, G. (2011): Temperature-dependent sex ratios in selected lines and crosses with a YY-male in Nile tilapia (Oreochromis niloticus). Aquaculture, 318, 79-84.

Western, P.S., Harry, J.L., Graves, J.A.M., Sinclair, A.H. (1999): TemperatureDependent Sex Determination: Upregulation of SOX9 Expression After Commitment to Male Development. Developmental Dynamics, 214, 171177.

Wohlfarth, G. and Wedekind, H. (1991): The heredity of sex determination in tilapias. Aquaculture Research, 92, 143-156.

Yamamoto, T.-O. (1969): Sex differentiation. In: Hoar, W.S. \& Randall, D.J.(eds.). Fish physiology, Vol. 3, Academic Press, New York, First Edition, ISBN 0123504031, pp. 117-175. 
Chapter 2

Additive, dominance, and reciprocal effects for temperature-dependent sex ratios of Nile tilapia (Oreochromis niloticus) using test cross diallels of selected lines 


\subsection{Abstract}

The phenotypic sex of Nile tilapia (Oreochromis niloticus) is governed by major and minor genetic factors as well as temperature. The temperature-dependent sex ratio is heritable and selection lines for high and low temperature susceptibility (high line and low line) had been produced. The current study provides first estimates of additive, dominance and reciprocal effects for the temperature-dependent sex of Nile tilapia using complete testcross diallels of the high and low line. A dominance effect of the low line was identified. Moreover, negative reciprocal effects on temperature-dependent sex ratios were found for high ${ }^{\lambda} \mathrm{x}$ low matings, indicating a maternal effect of the low line. Estimation of the heritabilities for the temperature-driven sex ratios under an animal model yielded in 0.74 for the highly and 0.51 for the weakly sensitive line. The results of this study consider important insights in the formation of temperaturedependent sex ratios and facilitate further studies on temperature-dependent sex differentiation in $O$. niloticus. Thereby, the diallels of the selected lines constitute excellent populations for future marker-based studies. This study provides helpful tools for establishing prospective breeding programs for temperature-driven masculinisation to substitute hormone treatments in tilapia production systems.

\subsection{Introduction}

The phenotypic sex of Nile tilapia (Oreochromis niloticus) is governed by major and minor genetic factors. Moreover, temperatures of $34{ }^{\circ} \mathrm{C}$ and more during juvenile stages have a masculinising effect (Baroiller et al., 1995; 1996). Tessema et al. (2006) postulated a highly effective temperature treatment at $36^{\circ} \mathrm{C}$ for 10 days if applied between day 10 to 20 post fertilization (dpf). However, this effect is strongly dependent on the sensitivity to temperature-dependent sex reversal and varies with the population (Tessema et al., 2006) and the combination of the parental animals (Baroiller and D'Cotta, 2001). Wes- 
sels and Hörstgen-Schwark (2007) and Baroiller and Clota (1998) assumed an additive model of temperature-driven sex ratios in Nile tilapia. This is not only hypothesised for temperature-driven sex in O. niloticus but also for the European sea bass (Dicentrarchus labrax) (Saillant et al., 2002) and the Atlantic silverside (Menidia menidia) (Conover and Kynard, 1981). Contrary to that, Baroiller and D'Cotta (2001) suggested, that only male breeders can sire either all sensitive or all insensitive progenies. Furthermore, the first indication for non-additive effects of temperature-dependent sex ratio inheritance in Nile tilapia can be found in the study of Tessema et al. (2006), showing a stronger effect of a low temperature-susceptible population on the progenies' temperaturedependent phenotypic sex.

Moreover, it has been proven that temperature-dependent sex ratio is a heritable trait and it can be selected for as a quantitative trait. Wessels and HörstgenSchwark $(2007 ; 2011)$ succeeded in the selection for a highly and weakly temperature-susceptible line. The percentage of males in temperature-treated progeny groups of the high and the low line was higher than $92 \%$ and less than $53 \%$, respectively, within three generations of selection. The cumulated realized heritability for the high and low line was 0.63 and 0.84 , respectively.

The present study is targeted on estimating components of inheritance on temperature susceptibility, applying complete testcross diallels to the selected lines, whereas each line represents a specific susceptibility to temperature-dependent sex ratios. The analysis of such testcross diallels shall help to understand the different pathways of inheritance of temperature-dependent phenotypic sex and, additionally, to gain more information about the genetic background of this trait. Results of this study consider helpful tools for further selection, for QTL-studies and for prospective breeding programs. 


\subsection{Material and methods}

\subsubsection{Mating design and temperature treatments}

Based on the selected lines for temperature-dependent male ratios by Wessels and Hörstgen-Schwark (2007; 2011), two complete testcross diallel for the low and the high line with reciprocals were carried out.

Thereby, the high line possesses high temperature susceptibility, reaching more than $92 \%$ males in temperature-treated progeny groups. The low line is selected for low temperature susceptibility, giving less than $53 \%$ males. Reciprocal line

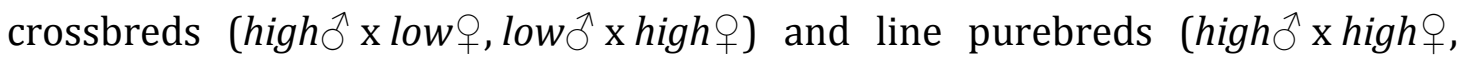
low $\widehat{\circlearrowleft} \mathrm{x} l o w$ ) were conducted for the first and the third generation of selection (Table 2). The parental animals were randomly selected from different families of the first and third generation of selection by avoiding inbreeding and producing at least half-sib progeny groups.

The spawners were individually PIT-tagged and kept in $300 \mathrm{~L}$ glass aquaria at a stocking density of $15 \mathrm{~kg} / \mathrm{m}^{3}$. After artificial fertilization, the progeny groups were incubated for 10 days at $28{ }^{\circ} \mathrm{C}$ until the hatched larvae were split in two groups per family, each comprising of 110 larvae. The control group was further kept at $28^{\circ} \mathrm{C}$ whereas the other group was kept at $36^{\circ} \mathrm{C}$ from days 10 to 20 post fertilization as previously described by Tessema et al. (2006). Temperature was checked three times a day. After ten days of treatment, the groups were raised at $28^{\circ} \mathrm{C}$ for at least two months in mesh covered $80 \mathrm{~L}$ glass aquaria. Fish of both the temperature-treated and the control groups were killed with an overdose of anaesthetics (diethylether) and the individual sex was examined microscopically using gonad squashes according to Guerrero and Shelton (1974).

\subsubsection{Statistical analysis}

Statistical analyses of the testcross diallels were performed using SAS/STAT $®$ software, version 9.2 (SAS Institute Inc, NC). Verification of a 1:1 proportion of males and females in the control groups was tested using the BINOMIAL option within the procedure FREQ in a one-way frequency table. Differences in male and female frequencies between control and treatment groups within the first and second testcross diallel were analysed by fitting a generalized linear model 
applying a logit link function using Proc GLIMMIX with sex coded as a binary trait (male $=1$; female $=0)$.

Estimation of the line additive, dominance and line reciprocal effects in the first and second testcross diallel were obtained with a logistic regression model based on Lozano et al. (2011) according to the model by Fimland (1983), adapted to the current data. The model (1) was applied for both diallels together and for each diallel separately in each control and temperature treatment $\left(28^{\circ} \mathrm{C}\right.$ or $\left.36^{\circ} \mathrm{C}\right)$. The model equation (1) and the definition of crossbreeding parameter coefficients following the notation in Lozano et al. (2011) are described below:

$\gamma_{i j k}=\mu+\sum_{i} a_{i} t_{i}+\sum_{i} r_{i} w_{i}+\sum_{i j} h_{i j} t_{i j}+e_{i j k}$

$\gamma_{i j k}=$ recorded sex with 1 for males and 0 for females of the $k$ th individual of the $i$ th and $j$ th line combination $(i=1,2 ; j=1,2)$;

$\mu=$ constant;

$a_{i}=$ regression coefficient of the additive genetic effect of the $i$ th line on the proportion of genes of the line;

$t_{i}=$ proportion of genes in the $k$ th individual originating from the $i$ th line $\left(t_{i}=0.0,0.5\right.$ or 1.0 and $\left.\sum t_{i}=1.0\right)$;

$r_{i}=$ regression coefficient of the reciprocal effect of the $i$ th line on the proportion of genes of the line;

$w_{i}=$ proportion of genes of the $k$ th offspring of the $i$ th line $\left(w_{i}=0.0\right.$ for purebreds, $w_{i}=-0.5$ for sire line origin, $w_{i}=0.5$ for dam line origin and $\sum w_{i}=0.0$;

$h_{i j}=$ regression coefficient of the total dominance effect for the $i$ th and $j$ th line combination on the proportion of genes originating from both reciprocals of the $i$ th and $j$ th lines $(i \neq j$ and $i j=j i$; thus with only two lines there is only one possible combination);

$t_{i j}=$ proportion of genes in the $k$ th individual of the $i$ th and $j$ th line combination $\left(t_{i j}=0.0\right.$ for $i=j, t_{i j}=t_{j i}=1.0$ for $i \neq j, \sum t_{i j}=0.0$ for purebreds and $\Sigma \mathrm{t}_{\mathrm{ij}}=1.0$ for line crosses);

$e_{i j k}=$ random error for the $k$ th offspring. 
Additionally, the heritabilities for the trait "sex" were estimated for the selection lines (high or low) and temperature treatment $\left(28^{\circ} \mathrm{C}\right.$ or $\left.36^{\circ} \mathrm{C}\right)$ using the data of the whole experiment for selection from the base population until the third generation of selection. Heritabilities were estimated under an animal model using the software DMU, Version 6, release 4.7 (Madsen and Jensen, 2007), treating sex as a binary trait and applying a probit link function.

\subsection{Results}

\subsubsection{Treatment-dependent sex ratios}

Sex ratios of the progenies from the diallels for both generations are listed in Table 2. Control sex ratios never differed from a 1:1 distribution, except for purebreds of the high line within the second diallel. This result has previously been detected by Wessels and Hörstgen-Schwark (2011).

In the first testcross diallel, the temperature treatment had significant masculinising effects in the crossbreds and purebreds compared to the control groups. In the second testcross diallel, temperature treatment caused significantly more males in both crossbreds and the purebreds of the high line, but not in the purebreds of the low line.

In the first diallel, the purebreds of the high line had the highest average temperature-dependent male ratios with $75.9 \%$ followed by the purebreds of the low line with $71.5 \%$ males. Both crossbreds showed average male ratios below $70 \%$ in the temperature treatment. Similarly to the first diallel, the purebreds of the high line showed the highest temperature-dependent male ratios and the high ${ }^{\lambda} \mathrm{x}$ low $\bigcirc$ matings showed lower male ratios than the reciprocals in the second diallel. In the subsequent generations, the purebreds of the high line reached higher male ratios and temperature-dependent male ratios in the low line approached a 1:1 distribution. On average, temperature-dependent male ratios were higher in the second testcross diallel. In both testcross diallels the

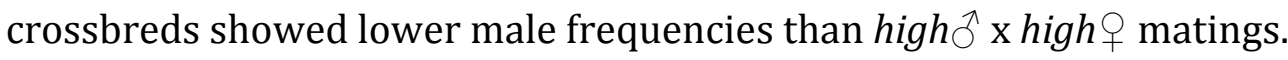


Table 2. Male ratios in control and treatment groups in two testcross diallels of the high and low line.

\begin{tabular}{|c|c|c|c|c|c|c|c|}
\hline & & Maternal & & & $\begin{array}{l}\text { Control } \\
\left(28^{\circ} \mathrm{C}\right)\end{array}$ & $\begin{array}{c}\text { Treatment }{ }^{\S} \\
\left(36^{\circ} \mathrm{C}\right)\end{array}$ & \\
\hline & line & line & n Families & n Individuals & \multicolumn{2}{|c|}{$\%$ males \pm sd } & \\
\hline Testcross & high & high & 29 & 4781 & $50.1 \pm 5.6$ & $75.9 \pm 15.3$ & $* * *$ \\
\hline \multirow[t]{3}{*}{ diallel 1} & low & low & 8 & 1655 & $51.3 \pm 4.1$ & $71.5 \pm 14.0$ & $* * *$ \\
\hline & high & low & 12 & 2849 & $49.8 \pm 2.8$ & $60.4 \pm 10.9$ & $*$ \\
\hline & low & high & 26 & 4493 & $49.5 \pm 4.1$ & $69.4 \pm 13.1$ & $* * *$ \\
\hline Testcross & high & high & 12 & 2028 & $54.1 \pm 8.7 \mathrm{a}$ & $92.7 \pm 6.6$ & $* * 1$ \\
\hline \multirow[t]{3}{*}{ diallel 2} & low & low & 20 & 2984 & $51.5 \pm 5.1$ & $50.4 \pm 9.8$ & n.s. ${ }^{1}$ \\
\hline & high & low & 8 & 1805 & $52.7 \pm 10.9$ & $65.9 \pm 8.7$ & $*$ \\
\hline & low & high & 11 & 1388 & $51.0 \pm 7.8$ & $69.8 \pm 12.4$ & $* *$ \\
\hline
\end{tabular}

\subsubsection{Additive line effects $\left(t_{i}\right)$}

The additive line effects for the high line are listed in Table 3, indicating the correlated additive line effects of the low line. Estimation of the additive line effect across both diallels in the temperature treatment revealed a highly significant $(\mathrm{p}<0.0001)$ positive effect of the high line on the occurrence of males. Estimation of odds ratio showed that the probability to produce males by temperature treatment is 1.85 times the probability for males in the low line. Within the control treatment, no difference in additive line effect was found ( $\mathrm{p}=0.67)$. When additive effects were estimated for each diallel separately, line differences within the first diallel were not significant for both temperature and control treatment. Within the second diallel, the additive line effect of the high line was highly significant for temperature but not for the control treatment. Point estimates of 
odds ratio revealed an 11.1-fold higher probability for the high line, to produce males by temperature treatment, when compared to the low line.

\subsubsection{Dominance effects $\left(t_{i j}=t_{j i}\right)$}

Overall, line crosses yielded negative dominance effects to the male frequencies. However, dominance effects were only significant if estimated for male frequencies in the temperature treatment $(\mathrm{p}<0.0001)$ with lower odds ratios within the second diallel (0.57) if compared to the first diallel (0.66) (Table 3).

\subsubsection{Reciprocal effects $\left(w_{i}\right)$}

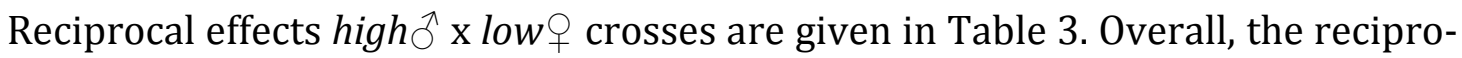
cals had no effect on the male frequencies in the control treatments. In the temperature treatments of both testcross diallels, high $\overbrace{}^{\lambda} \mathrm{x} l o w \bigcirc$ matings showed a negative effect on male frequencies (odds ratio $=0.77$ ) compared to the recipro-

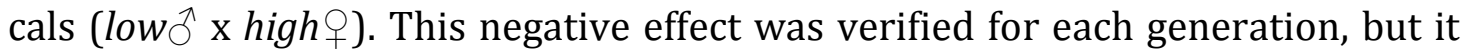
was only significant in the first diallel (odds ratio $=0.71 ; \mathrm{p}<0.0001$ ).

\subsubsection{Heritabilities $\left(h^{2}\right)$}

Heritabilities for the phenotypic sex in the control treatment approximated zero. In contrast to that, estimation of $\mathrm{h}^{2}$ for the phenotypic sex in the temperaturetreated groups resulted in higher values. The combination of both lines resulted in an $\mathrm{h}^{2}$ of $0.28 \pm 0.03$ for temperature-dependent sex ratios, whereas the high and low line showed values of $0.74 \pm 0.03$ and $0.52 \pm 0.04$, respectively. 
Table 3. Maximum-likelihood and odds ratio estimation of the line additive $\left(\boldsymbol{t}_{\boldsymbol{i}}\right)$, line reciprocal $\left(\boldsymbol{w}_{\boldsymbol{i}}\right)$ and dominance effects $\left(\boldsymbol{t}_{i j}\right)$ in the first and second testcross diallel (diallel 1 and diallel 2) of the high and low temperature-susceptible lines.

\begin{tabular}{|c|c|c|c|c|c|c|c|c|c|}
\hline \multirow[b]{2}{*}{ Generation } & \multirow[b]{2}{*}{ Treatment } & \multirow[b]{2}{*}{ Effect } & \multicolumn{4}{|c|}{ Maximum-likelihood estimates } & \multicolumn{3}{|c|}{ Odds ratio estimates } \\
\hline & & & Estimate & se & Wald $\chi^{2}$ & $\mathbf{p}$ & Point estimate & $95 \%$ Wal & nce limits \\
\hline \multirow[t]{3}{*}{ diallel $1+2$} & $36^{\circ} \mathrm{C}$ & $t_{i}$ & 1.05 & 0.06 & 318.74 & $<0.0001$ & 2.85 & 2.54 & 3.20 \\
\hline & & $w_{i}$ & -0.26 & 0.06 & 19.12 & $<0.0001$ & 0.77 & 0.69 & 0.87 \\
\hline & & $t_{i j}$ & -0.22 & 0.04 & 27.50 & $<0.0001$ & 0.80 & 0.74 & 0.87 \\
\hline \multirow[t]{3}{*}{ diallel $1+2$} & $28^{\circ} \mathrm{C}$ & $t_{i}$ & -0.02 & 0.05 & 0.18 & 0.67 & 0.98 & 0.88 & 1.09 \\
\hline & & $w_{i}$ & 0.06 & 0.06 & 1.32 & 0.25 & 1.07 & 0.96 & 1.19 \\
\hline & & $t_{i j}$ & -0.04 & 0.04 & 1.22 & 0.27 & 0.96 & 0.89 & 1.03 \\
\hline \multirow[t]{3}{*}{ diallel 1} & $36^{\circ} \mathrm{C}$ & $t_{i}$ & 0.12 & 0.09 & 1.80 & 0.18 & 1.13 & 0.95 & 1.34 \\
\hline & & $w_{i}$ & -0.35 & 0.07 & 24.51 & $<0.0001$ & 0.71 & 0.61 & 0.81 \\
\hline & & $t_{i j}$ & -0.42 & 0.06 & 54.51 & $<0.0001$ & 0.66 & 0.59 & 0.73 \\
\hline \multirow[t]{3}{*}{ diallel 1} & $28^{\circ} \mathrm{C}$ & $t_{i}$ & -0.03 & 0.08 & 0.15 & 0.70 & 0.97 & 0.83 & 1.14 \\
\hline & & $w_{i}$ & 0.06 & 0.07 & 0.80 & 0.37 & 1.06 & 0.93 & 1.21 \\
\hline & & $t_{i j}$ & -0.04 & 0.05 & 0.53 & 0.47 & 0.96 & 0.87 & 1.07 \\
\hline \multirow[t]{3}{*}{ diallel 2} & $36^{\circ} \mathrm{C}$ & $t_{i}$ & 2.49 & 0.13 & 369.22 & $<0.0001$ & 12.11 & 9.39 & 15.62 \\
\hline & & $w_{i}$ & -0.05 & 0.11 & 0.25 & 0.61 & 0.95 & 0.77 & 1.17 \\
\hline & & $t_{i j}$ & -0.56 & 0.08 & 44.22 & $<0.0001$ & 0.57 & 0.48 & 0.67 \\
\hline \multirow{3}{*}{ diallel 2} & $28^{\circ} \mathrm{C}$ & $t_{i}$ & 0.06 & 0.08 & 0.51 & 0.48 & 1.06 & 0.90 & 1.25 \\
\hline & & $w_{i}$ & 0.06 & 0.10 & 0.33 & 0.57 & 1.06 & 0.87 & 1.29 \\
\hline & & $t_{i j}$ & -0.03 & 0.07 & 0.25 & 0.61 & 0.97 & 0.85 & 1.10 \\
\hline
\end{tabular}

(se = standad error; $t_{i}=$ additive effect of the high line; $w_{i}=$ reciprocal effect of line cross high $\hat{\mathrm{x}} \mathrm{x}$ low ${ }_{+} ; t_{i j}=$ dominance effect of line crosses) 


\subsection{Discussion}

The current study provides first estimates of additive, dominance and reciprocal effects for the temperature-dependent sex of $O$. niloticus using complete testcross diallels of lines selected for high and low temperature susceptibility (Wessels \& Hörstgen-Schwark, 2007; 2011). By estimating the additive effects of the selection lines as well as the heritabilities for temperature-dependent male ratios, the findings by Wessels \& Hörstgen-Schwark $(2007$; 2011) concerning a generally 1:1 distribution of control sex ratios irrespective of the direction of selection could be verified. Heritabilities for sex ratios in the control groups were generally close to zero. Additionally, no significant line additive, dominance or reciprocal effect for control sex ratios was found for the selection lines. In contrast, Lester et al. (1989) estimated heritabilities of 0.26 for sex ratios of $O$. niloticus at normal rearing temperatures. It can be suggested, that these higher heritabilities were due to uncontrolled environmental conditions during juvenile stages, and temperature effects could not completely be neglected as an influence on the sex ratios in the study by Lester et al. (1989).

High narrow sense heritabilities for the temperature-dependent sex were verified. However, the cumulated heritability for both lines decreased by applying the animal model compared to the estimates of the realized heritabilities $\left(\mathrm{h}_{R}^{2}\right)$ by Wessels \& Hörstgen-Schwark (2011). Furthermore, Wessels \& Hörstgen-Schwark (2011) estimated higher $\mathrm{h}_{R}^{2}$ for the low line compared to the high line. In the current study, $\mathrm{h}^{2}$ is higher for the high line over all three generations of selection. Thereby, narrow sense heritabilities and realized heritabilities are not comparable, because $\mathrm{h}_{R}^{2}$ depends on the response to selection.

A negative dominance effect was found for the crossbreds in both diallels, indicating a dominance effect of the low line. It could be assumed that low susceptibility to high rearing temperature is connected to a stronger effect of the major genetic sex determining factors. Therefore, the selection for low temperature sensitivity could be related to a selection for a stronger effect of major sex determining factors and the high temperature-sensitive line has been selected for a lower effect of the major sex determining factor. However, Wessels \& Hörstgen-Schwark (2011) reported a paradoxical feminising effect of high rearing temperatures in 
matings of a YY-male with females from the high and low line as well as in two families of the low line. Thereby, they supposed that temperature can have both masculinising and feminising effects. However, the feminising effect in the low line was still low.

Grossen et al. (2011) proposed that in a quantitative genetics perspective, sex in general can be seen as a threshold trait that depends on an underlying liability factor which is under both genetic and environmental influence. This hypothesis can directly be applied to the current findings. It can be suggested, that more and stronger liability factors for the temperature-driven sex are accumulated in the high line than in the low line. The study by Tessema et al. (2006) could support these observations. In the crossings of two populations of $O$. niloticus, the average temperature-dependent male ratio of the population crosses (59.8\%) was lower than the average ratio of the purebreds (69.9\%), indicating a negative effect of the less temperature susceptible population.

In all conducted reciprocal line crosses, the sex ratios did not follow an additive genetic model. The dominance and reciprocal effects degraded due to the subsequent selection of the lines. The decreasing dominance effect in the second testcross diallel is contradictory. A stronger non-additive gene action would be expected in the crossbreds due to the increasing differentiation of the selected lines (Lynch and Walsh, 1998). Otherwise, it could be suggested that the high line accumulated strong temperature liability factors by further selection and the effect of the low line was maintained. Moreover, a negative reciprocal effect was found for high $\widehat{\supset}$ x low $\uparrow$ crossbreds. This may indicate a stronger influence of the low line if used on the maternal side. However, this effect was only significant for the first testcross diallel but also distinct in the second diallel. Within the high line, such a maternal effect could not be estimated. Maternal effects on environmental sex determination (ESD) have been detected for different species (Conover and Kynard, 1981; Ewert et al., 1994; Lang and Andrews, 1994; Luckenbach et al., 2003; Warner and Shine, 2005) resulting from different spawning seasons or oviposition sites where the progeny is exposed to environmental conditions which may influence the phenotypic sex. In this study, such factors for the maternal effect observed in the low line can be excluded. Maternal breeders were stocked under standardized conditions and the fertilisation took place artificially. 
Therefore, genetic maternal effects were rather due to genetic conflicts of maternal and zygotic sex determiners (Werren and Hatcher, 2000), cytoplasmatic effects as well as nDNA - mtDNA interaction or genomic imprinting (Werren and Beukeboom, 1998).

The observed additive, dominance and reciprocal effects on the susceptibility to temperature-dependent male ratios of 0 . niloticus reveal new insights to the inheritance of this trait. The results facilitate further studies on temperaturedependent sex differentiation in $O$. niloticus such as marker assisted genotype examinations. For marker based association studies, the diallels of the selected lines constitute excellent mapping populations.

\subsection{References}

Baroiller, J.F., Chourrout, D., Fostier, A., Jalabert, B. (1995): Temperature and sex-chromosomes govern sex ratios of the mouthbrooding cichlid fish Oreochromis niloticus. Journal of Experimental Zoology, 273, 216-223.

Baroiller, J.F., Fostier, A., Cauty, C., Rognon, X., Jalabert, B. (1996): Effects of high rearing temperatures on sex ratio of progeny from sex reversed males of Oreochromis niloticus. In: Pullin RSV, Lazard J, Legendre M, Amon Kothias JB, Pauly D (eds): The Third International Symposium on Tilapia in Aquaculture ICLARM Conference Proceedings, 41, 246-256.

Baroiller, J.F. and Clota, F. (1998): Interactions between temperature effects and genotype on Oreochromis niloticus sex determination. Journal of Experimental Zoology, 281, 507 (abstract).

Baroiller, J. F., and D'Cotta, H. (2001): Environment and sex determination in farmed fish. Comparative Biochemistry and Physiology, 130, 399-409.

Conover, D. O. and Kynard, B. E. (1981): Environmental sex determination: interaction of temperature and genotype in a fish. Science, 213, 577-579.

Ewert, M.A., Jackson, D.R., Nelson, C.E. (1994): Patterns of temperaturedependent sex determination in turtles. Journal of Experimental Zoology, 270, 3-15. 
Fimland, E. (1983): Methods of estimating the effects of heterosis. Zeitschrift für Tierzüchtung und Züchtungsbiologie, 100, 3-8.

Guerrero, R.D. and Shelton, W.L. (1974): Aceto-carmine squash method for sexing juvenile fishes. Progressive Fish-Culturist, 36, 56-56.

Lang, J.W. and Andrews, H.V. (1994): Temperature-dependent sex determination in crocodilians. Journal of Experimental Zoology, 270, 28-44.

Lester, L., Lawson, K., Abella, T., Palada, M. (1989): Estimated heritability of sex ratio and sexual dimorphism in tilapia. Aquaculture Research 20, 369-380.

Lozano, C., Gjerde, B., Bentsen, H.B., Dionisio, E.E., Rye, M. (2011): Estimates of strain additive genetic, heterosis and reciprocal effects for male proportion in Nile tilapia, Oreochromis niloticus L. Aquaculture, 312, 32-42.

Luckenbach, J.A., Godwin, J., Daniels, H.V., Borski, R.J. (2003): Gonadal differentiation and effects of temperature on sex determination in southern flounder (Paralichthys lethostigma). Aquaculture, 216, 315-327.

Lynch, M. and Walsh, J.B. (1998): Genetics and Analysis of Quantitative Traits. Sinauer Assocs., Inc., Sunderland (MA).

Madsen, P. and Jensen, J. (2007): A User's Guide to DMU, Version 6, release 47. Danish Institute of Agriculture and Science, Tjele, Denmark.

Saillant, E., Fostier, A., Haffray, P., Menu, B., Thimonier, J., Chatain, B. (2002): Temperature effects and genotype-temperature interactions on sex determination in the European sea bass (Dicentrarchus labrax L.). Journal of Experimental Zoology, 292, 494-505.

Tessema, M., Müller-Belecke, A., Hörstgen-Schwark, G. (2006): Effect of rearing temperatures on the sex ratios of Oreochromis niloticus populations. Aquaculture, 258, 270-277.

Warner, D.A. and Shine, R. (2005): The adaptive significance of temperaturedependent sex determination: Experimental tests with a short-lived lizard. Evolution, 59, 2209-2221.

Werren, J.H. and Hatcher, M.J. (2000): Maternal-zygotic gene conflict over sex determination: Effects of inbreeding. Genetics, 155, 1469-1479. 
Werren, J.H. and Beukeboom, L.W. (1998): Sex determination, sex ratios, and genetic conflict. Annual Review of Ecology, Evolution, and Systematics, 29, 233-261.

Wessels, S. and Hörstgen-Schwark, G. (2007): Selection experiments to increase the proportion of males in Nile tilapia (Oreochromis niloticus) by means of temperature treatment. Aquaculture, 272, S80-S87.

Wessels, S. and Hörstgen-Schwark, G. (2011): Temperature-dependent sex ratios in selected lines and crosses with a YY-male in Nile tilapia (Oreochromis niloticus). Aquaculture, 318, 79-84. 


\title{
Chapter 3
}

\author{
First evidence for family-specific QTL \\ for temperature-dependent sex reversal \\ in Nile tilapia \\ (Oreochromis niloticus)
}

(Manuscript has been accepted for publication in "Sexual Development", 23.04.2012, Manuscript No.: 201201005).

\footnotetext{
Liane-Magdalena Lühmann 1,*, Christoph Knorr 2, Gabriele HörstgenSchwark ${ }^{1}$, Stephan Wessels ${ }^{1}$

1 Department of Animal Sciences, Division of Aquaculture and Water Ecology, Albrecht-Thaer-Weg 3, D-37075 Göttingen, Germany

${ }^{2}$ Department of Animal Sciences, Division of Reproduction and Biotechnology of Livestock,

Burckhardtweg 2, D-37077 Göttingen, Germany

*corresponding author: Tel.: +49 55139 19336; fax: +49 55139 5587; E-mail:

lluehma@gwdg.de
} 


\subsection{Abstract}

This study for the first time screens microsatellite markers for associations with the temperature-dependent sex of Oreochromis niloticus. Previous studies revealed markers on linkage groups (LG) 1, 3, and 23 to be linked to the phenotypic sex of Oreochromis spp. at normal rearing temperatures. Moreover, candidate genes for sex determination and differentiation have been mapped to these linkage groups. Here, six families of a temperature-treated genetically all-female (XX) $\mathrm{F}_{1}$-population were genotyped for 21 microsatellites on the three LGs. No population-wide QTL (quantitative trait loci) or marker trait associations could be detected. However, family-specific QTL were found on LG 1, flanked by UNH995 and UNH104, on LG 3 at the position of GM213, and on LG 23, next to GM283. Moreover, family-specific single marker associations for UNH995 and UNH104 on LG 1, GM213 on LG 3, as well as for UNH898 and GM283 on LG 23 were detected. Yet, marker trait associations could not explain the temperaturedependent sex of all fish in the respective families. The molecular cue for the temperature-dependent sex in Nile tilapia might partially coincide with allelic variants at major and minor genetic sex determining factors. Moreover, additional QTL contributing to variable liabilities towards temperature might persist on other LGs.

Key words: temperature, sex determination, TSD, GSD, Nile tilapia, QTL, sex reversal 


\subsection{Introduction}

The determination of sex in Nile tilapia (Oreochromis niloticus) is a very complex and not yet completely understood mechanism. O. niloticus has a genetic sex determination (GSD) system with male heterogamety $(\mathrm{XX} / \mathrm{XY})$ as the major genetic factor (Mair et al., 1991). It is, however, postulated that further minor autosomal factors are able to override the major genetic sex determination (Mair et al., 1991; Müller-Belecke and Hörstgen-Schwark, 1995). Furthermore, elevated temperatures of $34^{\circ} \mathrm{C}$ and more are also capable to switch the sex of genetically female (XX) Nile tilapia into phenotypic males (Baroiller et al., 1995a), if applied during the critical sensitive period when the gonads are still sexually undifferentiated (Baroiller et al., 1995a; b). Tessema et al. (2006) postulated a highly effective temperature treatment for 10 days at $36{ }^{\circ} \mathrm{C}$ between day 10 to 20 post fertilization (dpf). Temperature-dependent phenotypic sex is under genetic control. Male ratios in temperature-treated progenies are strongly dependent on the population and on the combination of the parental animals (Baroiller and D'Cotta, 2001; Tessema et al., 2006). Moreover, it has been proven that temperature-dependent sex ratio is a heritable trait and it can be selected for as a quantitative trait. Wessels and Hörstgen-Schwark (2007; 2011) succeeded in the selection for high and low temperature response: within three generations of selection the percentage of males in temperature-treated progeny groups of the high and the low line was more than $92 \%$ and less than

$53 \%$, respectively. The cumulated realized heritability for the high and low line was 0.63 and 0.84 , respectively.

A comprehensive linkage map, derived from a $\mathrm{F}_{2}$-family of the hybrid cross Oreochromis niloticus x Oreochromis aureus, exists for tilapia (Lee et al., 2005). The map spans $1311 \mathrm{cM}$ in 24 linkage groups (LG). It consists of 525 microsatellite markers and 21 gene-based markers. Associations with the phenotypic sex in Oreochromis spp. and interspecies crosses were reported for markers on LG 1, 3, and 23 (Shirak et al., 2002; Lee et al., 2003; 2004; 2005; 2011; Cnaani et al., 2004). Furthermore, several candidate genes (amh, dmo, dmrta2, sox14 and $w t 1 b)$ as putative master key regulators of sex determination in tilapia were in 
addition mapped to LG 23 (Lee et al., 2005; Shirak et al., 2006; Lee and Kocher, 2007; Cnaani et al., 2008).

In $O$. niloticus, the major sex determiner has been mapped to the chromosomal region between microsatellites GM201 and UNH104 on LG 1 (11 cM distance) (Lee et al., 2003; Lee and Kocher, 2007). Later, Cnaani et al. (2008) mapped the major sex determiner to a $1 \mathrm{cM}$ region on the same chromosome flanked by UNH104 and UNH995. Recently, Eshel et al. (2011) described a strong association of the microsatellite UNH898 on LG 23 with the phenotypic sex in mixed sex (XX/XY) populations of 0 . niloticus. UNH898 has been mapped next to amh (1 cM distance) (Shirak et al., 2006), which shows a strongly sex dimorphic expression in brains of 0 . niloticus at $14 \mathrm{dpf}$ shortly before the initial start of the gonadal differentiation (Poonlaphdecha et al., 2011). Despite of the suggestive associations with the major sex determiner in different populations, the markers on the above mentioned LG 1, 3, and 23 do not explain the sex ratio in all investigated families. Thus, it is hypothesized that only the interaction of major and minor genetic factors together with temperature-dependent factors will contribute to finally explain the variety of sex ratios (Lee and Kocher, 2007; Cnaani et al., 2008).

There is no ample knowledge of genetic components contributing to temperature effects on the phenotypic sex in Nile tilapia. So far, a key role in temperature-dependent sex expression in Nile tilapia was only shown for cyp19a, due to reduced expression in undifferentiated gonads of temperature-treated allfemale fish (D'Cotta et al., 2001). Cyp19a was mapped to LG 1, flanked by GM633 and UNH985 (Shirak et al., 2006; Lee and Kocher, 2007). The evolutionary role, the development and the interdependence of GSD, temperature effects on the phenotypic sex, and temperature-dependent sex determination (TSD) are still under discussion (Sarre et al., 2004; Bull, 2008; Ospina-Alvarez and Piferrer, 2008; Shoemaker and Crews, 2009). Bull (1980) proposed that GSD and TSD systems were mutually exclusive. In Nile tilapia, a coexistence of GSD and temperature effects on the phenotypic sex has been postulated (Wessels and Hörstgen-Schwark, 2007). However, it is still questionable if a genetic correlation between GSD and temperature effects on the phenotypic sex persists. To test for this hypothesis, 21 microsatellite markers on LG 1, 3, and 23 were inves- 
tigated to prove any putative associations with the temperature-dependent sex of 180 temperature-treated fish derived from a cross between normal females $(\mathrm{XX})$ and temperature sex reversed males $\left(\triangle \partial^{\lambda} \mathrm{XX}\right)$.

\subsection{Materials and Methods}

\subsubsection{Mapping Population}

A genetically all-female $(\mathrm{XX})$ mapping population of six genetically unrelated $\mathrm{F}_{1}$ families was established, derived from the Lake Manzala population (Egypt) (Table 4). Six XX-females from the low line and five temperature sex reversed $\triangle \supset^{\lambda} \mathrm{XX}$-males from the high line originating from a previous selection experiment were used as parents (Wessels and Hörstgen-Schwark, 2007; 2011). The temperature-dependent male ratios in the families of the low line females were less than $60 \%$. In the sire families, the temperature-dependent male ratios were more than $93 \%$. The males were previously tested for their genetic sex (XX/XY) by progeny testing (Lühmann et al., 2009), and finclips were collected from each individual $(n=11)$. For individual identification, all fish were tagged using passive integrated transponders (PIT). After artificial fertilization, the progeny groups were incubated for 10 days at $28{ }^{\circ} \mathrm{C}$ until the larvae were split in two groups per family, each comprising 110 larvae. The control group was kept at $28^{\circ} \mathrm{C}$ and the temperature treatment was carried out at $36^{\circ} \mathrm{C}$ from days 10 to 20 post fertilization as previously described by Tessema et al. (2006). Temperature was checked three times a day. After ten days of treatment, the groups were raised separately at $28{ }^{\circ} \mathrm{C}$ for at least two months in mesh covered 80 L glass aquaria. Finally, 15 males and 15 females of each of the six temperature-treated groups were sexed alive by examination of the genital papilla and fin clips were taken as DNA source. Surplus fish of both the temperature-treated groups and the control groups were killed by an overdose of anaesthetics (diethylether) and the individual sex was microscopically examined using gonad squashes according to Guerrero and Shelton (1974). 


\subsubsection{Genotyping of microsatellite markers}

The 21 microsatellite markers (Table 5) used in this study were chosen from linkage groups 1, 3, and 23 published by Lee et al. (2005). The selection of microsatellites aimed to achieve an even distribution over the linkage groups with an average distance of $9.5 \mathrm{cM}$ per LG.

DNA was isolated from the fin clips by phenol-chlorophorm extraction (Chomczynski and Sacchi, 1987). Evaluation of microsatellites and allele calling were done on the ABI PRISM 3100 Genetic Analyzer with the ABI-softwares GENESCAN 3.7 and GENOTYPER 3.6 using GENESCAN ${ }^{\mathrm{TM}}-500$ ROX $^{\mathrm{TM}}$ as internal size standards. Multiplex assays (A to $\mathrm{H}$ ) of two to four primer pairs were optimized (Table 5). PCR was carried out using 40 ng of genomic DNA with 1 x MultiplexMix (Qiagen, Hilden, Germany), 0.5 x Q-Solution (Qiagen), 2.8 - 14 pmol of each primer (one labelled at the 5'end alternatively with fluorescent dyes 6FAM, CY3 or HEX) in a volume of $14 \mu$ l. The cycling conditions used were: 35 cycles at $92^{\circ} \mathrm{C}$ for $30 \mathrm{sec}$, a multiplex specific annealing temperature of $54{ }^{\circ} \mathrm{C}, 57$ ${ }^{\circ} \mathrm{C}$ or $62{ }^{\circ} \mathrm{C}$ for $30 \mathrm{sec}$ and an extension period of $35 \mathrm{sec}$ at $72{ }^{\circ} \mathrm{C}$ with an initial denaturation for $5 \mathrm{~min}$ at $95^{\circ} \mathrm{C}$ and a final extension at $72{ }^{\circ} \mathrm{C}$ for $5 \mathrm{~min}$. PCR reactions were performed using the Biometra T-Gradient thermocycler (Biometra, Goettingen, Germany).

\subsubsection{Statistical analysis}

For the examination of marker properties, the expected heterozygosity (also known as allelic diversity) (He) and the observed heterozygosity (Ho) were estimated for each microsatellite marker using the procedure ALLELE within the SAS/Genetics $®$ software, version 9.2 (SAS Institute Inc, N.C., USA).

The linkage map for the genetically all-female $(X X) F_{1}$-population was constructed using JOINMAP 4.0 (Kyazma, Wageningen, Netherlands) (Van Ooijen, 2006) under the cross population (CP) function. The Kosambi mapping function was applied with LOD scores of $\geq 3$. Maps of the six single $F_{1}$-families were constructed and merged to one integrated linkage map. The comparative map charts of the current linkage map and the reference mapping by Lee et al. 
(2005) was drawn using the software MapChart 2.1 (Voorrips, 2002). Both linkage maps were compared by drawing homologous loci within MapChart 2.1.

The QTL (quantitative trait loci) mapping was carried out using GridQTL 2.1.5 (Seaton et al., 2006). As a dependent variable, temperature-dependent phenotypic sex of the genetically all-female $\mathrm{F}_{1}$-population was considered as a binary trait, coded 1 for males and 2 for females. A chromosome-wide analysis, assuming a single QTL, was performed under the Visscher and Hopper (2001) option in $1 \mathrm{cM}$ intervals. The chromosome wide significance thresholds for $\mathrm{p}=0.05$ and $\mathrm{p}=0.01$ were determined by bootstrapping with 1000 iterations. Additionally, Pearson $\chi^{2}$ statistics (SAS/STAT® software, version 9.2 (SAS Institute Inc, NC), Proc GLIMMIX) was performed to test for linkage between the single marker genotypes and the temperature-dependent phenotypic sex at the population and the family level. Families showing significant marker trait associations were analysed again for the respective marker genotypes by Fisher's exact test. Additionally, a family specific QTL mapping was performed with GridQTL 2.1.5 (Seaton et al., 2006) for the respective families using the same options as in the population wide QTL analysis described before.

\subsection{Results}

\subsubsection{Temperature-dependent phenotypic sex of the mapping population}

No phenotypic males were observed in the control groups, except for family 6 with two males out of 96 fish (2.1\%). Contrary to that, the temperature-treated groups showed $33.5 \%$ males on average. The lowest percentage of males (17.5\%) was observed in family 5 , and the highest percentage of males (61.0\%) was observed in family 2 (Table 4 ).

\subsubsection{Marker properties}

In the parental generation, two to six alleles per locus were identified. Over all loci, the average number of alleles was 4.2 (Table 5). In general, the chosen microsatellites were highly informative. A proportion of $2.1 \%$ missing alleles was found in the mapping population. The average $\mathrm{He}$ and Ho value were 0.61 and 
0.68, respectively. Two loci (UNH106 and UNH982) showed Ho and He values of less than 0.5 (Table 5). Five of the 21 loci revealed up to three null alleles in specific families or in the whole mapping population (Table 5). The remaining missing genotypes for these markers could be deduced from parental genotypes in most cases. For UNH982, the null alleles 112 and 118 were found in one family, with both alleles coming from the maternal genotype. It was not possible to deduce these alleles and they were set as missing values. For UNH216, the null alleles could not be deduced for family 6 and were thus set as missing values. Additionally, the genotyping of family 4 for UNH216 was insufficient. Only five males and ten females were genotyped. Therefore, $1.2 \%$ of all missing alleles resulted from missing genotypes at the loci UNH216. However, UNH216 has been included in all statistical analysis.

Table 4. Number of males and females and male ratios in the control $\left(28{ }^{\circ} \mathrm{C}\right)$ and temperature-treated $\left(36^{\circ} \mathrm{C}\right)$ groups of the genetically all-female $\mathrm{F}_{1}$ families.

\begin{tabular}{c|cccc}
\hline Family & Treatment & $\begin{array}{c}\text { n Males } \\
(\boldsymbol{\Sigma} \mathbf{~ 1 8 9 )}\end{array}$ & $\begin{array}{c}\text { n Females } \\
\mathbf{( \Sigma} \text { 982) }\end{array}$ & $\begin{array}{c}\text { Male ratio } \\
\text { (\%) }\end{array}$ \\
\hline 1 & $28^{\circ} \mathrm{C}$ & 0 & 107 & 0.0 \\
1 & $36^{\circ} \mathrm{C}$ & 37 & 63 & 37.0 \\
\hline 2 & $28^{\circ} \mathrm{C}$ & 0 & 101 & 0.0 \\
2 & $36^{\circ} \mathrm{C}$ & 47 & 30 & 61.0 \\
\hline 3 & $28^{\circ} \mathrm{C}$ & 0 & 108 & 0.0 \\
3 & $36^{\circ} \mathrm{C}$ & 27 & 79 & 25.5 \\
\hline 4 & $28^{\circ} \mathrm{C}$ & 0 & 95 & 0.0 \\
4 & $36^{\circ} \mathrm{C}$ & 19 & 81 & 19.0 \\
\hline 5 & $28^{\circ} \mathrm{C}$ & 0 & 96 & 0.0 \\
5 & $36^{\circ} \mathrm{C}$ & 17 & 80 & 17.5 \\
\hline 6 & $28^{\circ} \mathrm{C}$ & 2 & 94 & 2.1 \\
\hline 6 & $36^{\circ} \mathrm{C}$ & 40 & 58 & 40.8 \\
\hline
\end{tabular}


Table 5. Characteristics of the chosen microsatellite markers with positions on the genetic map by Lee et al. (2005) and marker trait association statistics $\left(\chi^{2}, p\right)$ for the temperature-dependent phenotypic sex.

\begin{tabular}{|c|c|c|c|c|c|c|c|c|c|c|}
\hline Locus & $\begin{array}{l}\text { GeneBank } \\
\text { Accession }\end{array}$ & LG & $\begin{array}{c}\text { Kosambi } \\
\text { cM }\end{array}$ & $\begin{array}{l}\text { Annealing } \\
\text { temp. }\left({ }^{\circ} \mathrm{C}\right)\end{array}$ & Multiplex & n Alleles & Ho & $\mathrm{He}$ & $\overline{\chi^{2}}$ & $\bar{p}$ \\
\hline GM633 & BV005530 & 1 & 0 & 57 & $\mathrm{~F}$ & 4 & 0.69 & 0.63 & 3.09 & 0.69 \\
\hline UNH985 & G68266 & 1 & 11 & 57 & D & 3 & 0.65 & 0.56 & 3.36 & 0.5 \\
\hline GM201 & BV005353 & 1 & 24 & 57 & E & 5 & 0.6 & 0.58 & 2.86 & 0.83 \\
\hline UNH995 & G68274 & 1 & 35 & 62 & G & 5 & 0.62 & 0.63 & 7.25 & 0.4 \\
\hline UNH104 & G12257 & 1 & 36 & 57 & $\mathrm{~F}$ & 5 & 0.65 & 0.63 & 7.45 & 0.38 \\
\hline GM258 & BV005380 & 1 & 46 & 62 & G & 3 & 0.74 & 0.61 & 1.61 & 0.81 \\
\hline UNH846 & G68185 & 1 & 54 & 54 & B & 4 & 0.74 & 0.64 & 3.56 & 0.83 \\
\hline GM354 & BV005419 & 3 & 0 & 62 & $\mathrm{H}$ & $5^{1}$ & 0.85 & 0.7 & 3.71 & 0.81 \\
\hline GM271 & BV005386 & 3 & 13 & 57 & $\mathrm{D}$ & $3^{2}$ & 0.72 & 0.54 & 0.92 & 0.99 \\
\hline GM213 & BV005364 & 3 & 25 & 54 & $\mathrm{C}$ & 3 & 0.62 & 0.55 & 6.89 & 0.14 \\
\hline UNH971 & G68259 & 3 & 39 & 57 & D & 6 & 0.87 & 0.71 & 3.26 & 0.92 \\
\hline GM150 & BV005333 & 3 & 49 & 54 & A & 4 & 0.67 & 0.61 & 10.18 & 0.12 \\
\hline UNH106 & G12259 & 3 & 80 & 54 & B & $3^{3}$ & 0.35 & 0.41 & 3.08 & 0.38 \\
\hline UNH982 & G68265 & 3 & 95 & 62 & G & $4^{4}$ & 0.24 & 0.22 & 1.21 & 0.75 \\
\hline GM557 & BV005493 & 23 & 0 & 62 & $\mathrm{H}$ & 4 & 0.71 & 0.66 & 1.98 & 0.92 \\
\hline UNH197 & G12348 & 23 & 9 & 57 & $\mathrm{D}$ & 4 & 0.69 & 0.72 & 10.87 & 0.14 \\
\hline GM283 & BV005394 & 23 & 22 & 57 & E & 6 & 0.84 & 0.74 & 8.34 & 0.21 \\
\hline UNH898 & G68215 & 23 & 23 & 62 & $\mathrm{H}$ & 4 & 0.59 & 0.62 & 10.37 & 0.32 \\
\hline UNH216 & G12367 & 23 & 25 & 54 & $\mathrm{C}$ & $3^{5}$ & 0.7 & 0.64 & 1.13 & 0.57 \\
\hline GM576 & BV005504 & 23 & 36 & 62 & $\mathrm{H}$ & 5 & 0.95 & 0.71 & 5.52 & 0.48 \\
\hline GM163 & BV005338 & 23 & 51 & 54 & A & 6 & 0.79 & 0.65 & 3.96 & 0.78 \\
\hline
\end{tabular}

(multiplex: loci with the same capitals were used together in one PCR assay; $n$ alleles: superscripts indicating null alleles (bp); $1=96$ (family 3), ${ }^{2}=\mathbf{1 0 7}$ (family 6), 132 (family $1,2,3,4$ ), ${ }^{3}=\mathbf{1 2 3}$ (family 2), 129 (family 3 ), ${ }^{4}=\mathbf{1 0 2}$ (family 4, 5), 112 \& 118 (family 2 ), ${ }^{5}=\mathbf{1 1 7}($ family 4,5 , 6), 119 (family 4, 5), 121 (family 1,3). 


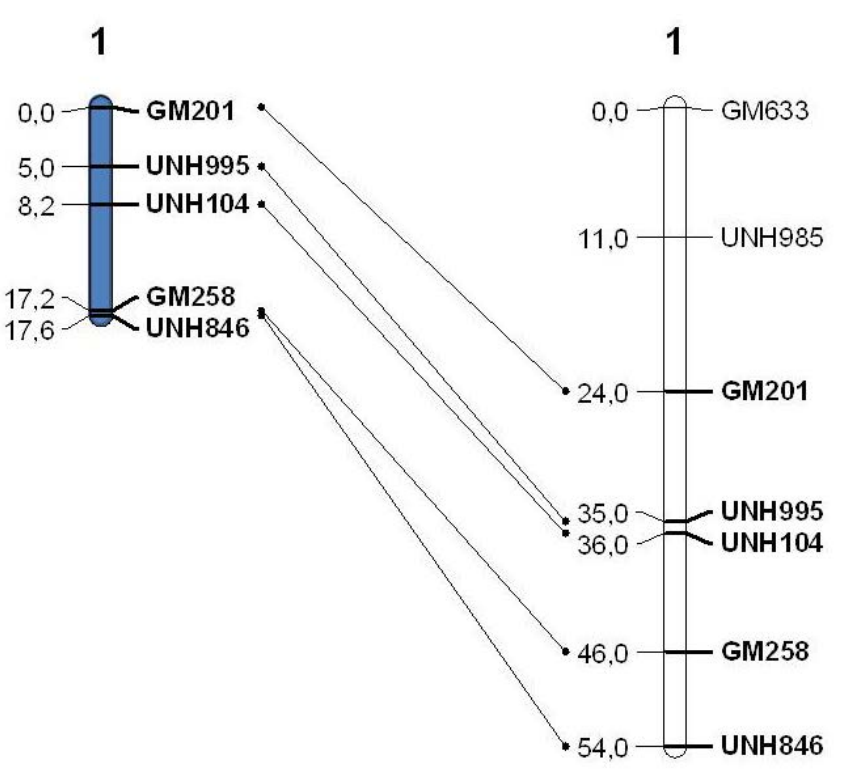

u

23

23

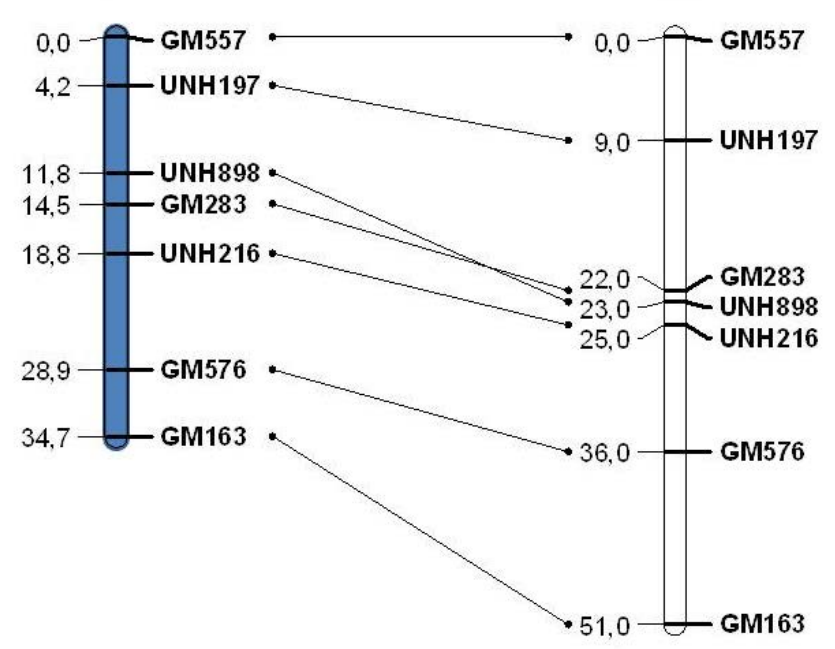

$3 a$

3

$3 \mathrm{~b}$

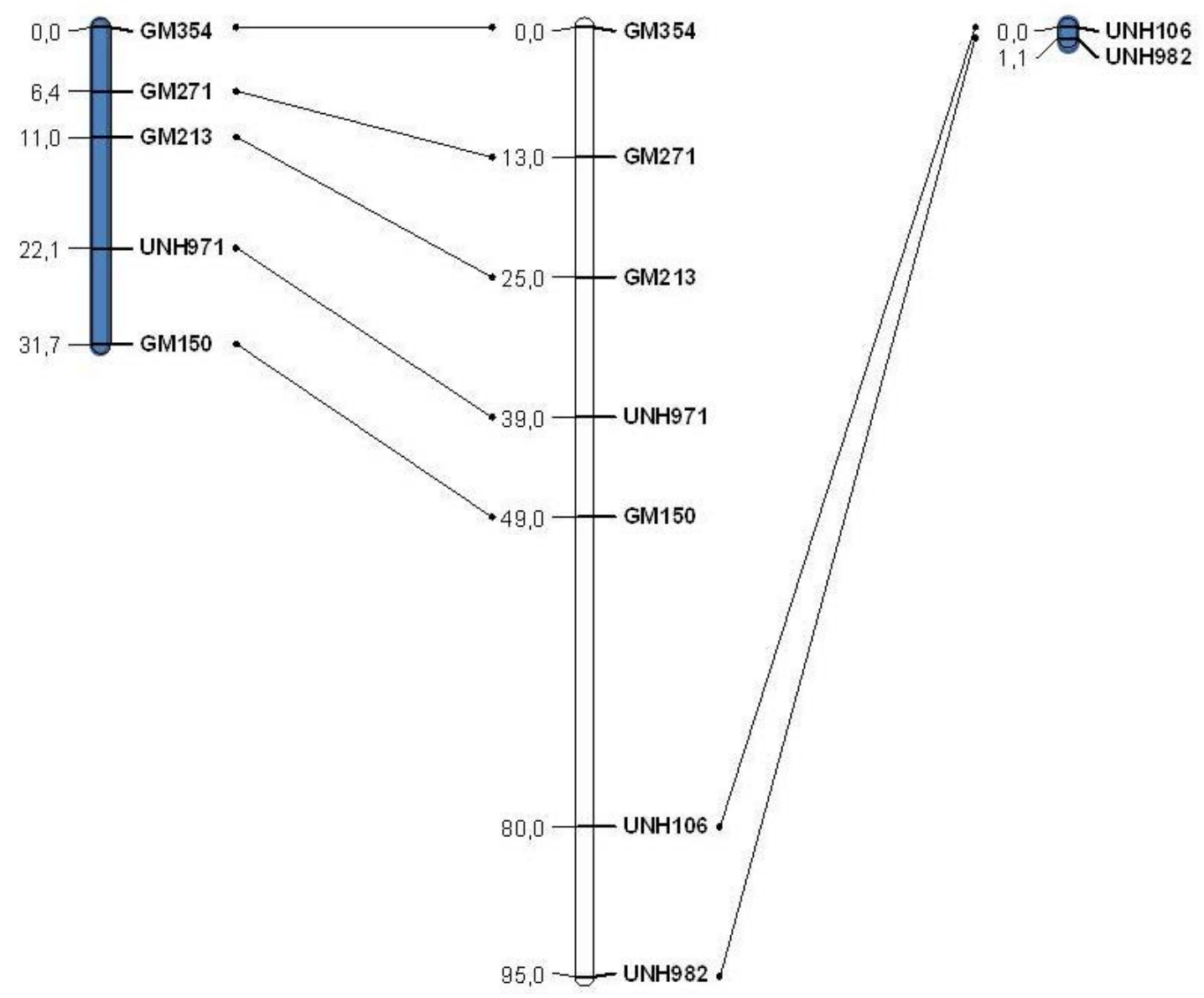

Figure 2. Comparison of the genetic linkage map of Lee et al. (2005) (white) and the combined linkage map of six genetically all-female (XX) temperaturetreated $\mathrm{F}_{1}$ families (blue) of 0 . niloticus. Marker distances in Kosambi cM are given to the left of each linkage group. 


\subsubsection{Linkage Map}

GM633 and UNH985 remained unmapped, but an integrated linkage map consisting of four LGs (LOD $\geq 3$; Figure 2) was constructed. The total map length was $85.1 \mathrm{cM}$ with an average marker distance of $4.8 \mathrm{cM}$. LG 1 was $17.6 \mathrm{cM}$ long with five markers having an average distance of $4.4 \mathrm{cM}$. LG 3a consisted of five markers with an average distance of $7.9 \mathrm{cM}$ and a total length of $31.7 \mathrm{cM}$. LG 3b included two markers with a distance of $1.1 \mathrm{cM}$. Seven markers were mapped to LG 23 over a total length of $34.7 \mathrm{cM}$ and an average marker distance of $5.8 \mathrm{cM}$.

\subsubsection{Marker trait associations for temperature-dependent phenotypic sex}

The population wide QTL search for the phenotypic sex of the temperaturetreated genetically all-female $\mathrm{F}_{1}$-population showed no significant QTL on any of the LGs (Table 6). LOD scores were as high as 1.1 for LG 23 and as low as 0.03 for LG 3b. F-values were below the F-statistic thresholds for $\mathrm{p}=0.05$.

Table 6. Population wide QTL statistics for temperature-dependent phenotypic sex in a genetically all-female $(\mathrm{XX})$ population of $O$. niloticus.

\begin{tabular}{c|ccc}
\hline LG & F statistic & $\begin{array}{c}\text { F statistics } \\
\text { threshold } \\
\text { (p=0.05) }\end{array}$ & LOD \\
\hline 1 & 3.600 & 6.870 & 0.781 \\
3a & 2.440 & 7.195 & 0.529 \\
$3 b$ & 0.130 & 5.291 & 0.029 \\
23 & 4.980 & 7.284 & 1.081 \\
\hline
\end{tabular}

Pearson $\chi^{2}$ test statistics for single marker associations did also not reveal significances at the population level (Table 5). However, the family based approach revealed several significant associations with the phenotypic sex: UNH995 and UNH104 on LG 1 in family 6, GM213 on LG 3a in family 2, and UNH898 (LG 23) and GM283 (LG 23) in family 4. Fisher's exact statistics for these five markers 
and the respective families are displayed in Table 7. The subsequent QTL studies using GridQTL confirmed the associations for families 2, 4, and 6 (Figures 3, 4 , and 5).

Furthermore, segregation distortions for GM283 and UNH898 genotypes were found for family 4 . The four genotypes per marker significantly differed from the expected Mendelian segregation of 1:1:1:1 $(\mathrm{p}<0.05)$.

Table 7. Number of males and females for each genotype of family-specific significantly associated loci with the temperature-dependent sex.

\begin{tabular}{|c|c|c|c|c|}
\hline Locus $\quad$ Family ${ }^{1}$ & $\mathbf{p}^{2}$ & Genotype 3 & n Males & n Females \\
\hline UNH995 family 6 & 0.025 & $172 / 220$ & 10 & 3 \\
\hline$(172 / 172 \times 172 / 220)$ & & $172 / 172$ & 5 & 12 \\
\hline UNH104 family 6 & 0.027 & $129 / 178$ & 11 & 4 \\
\hline$(129 / 129 \times 129 / 178)$ & & $129 / 129$ & 4 & 11 \\
\hline GM213 family 2 & 0.025 & $76 / 83$ & 10 & 3 \\
\hline$(76 / 83 \times 83 / 83)$ & & $83 / 83$ & 5 & 12 \\
\hline UNH898 family 4 & 0.037 & $254 / 274$ & 1 & 4 \\
\hline \multirow[t]{3}{*}{$(254 / 274 \times 254 / 262)$} & & $254 / 254$ & 10 & 4 \\
\hline & & $262 / 274$ & 1 & 6 \\
\hline & & $254 / 262$ & 2 & 1 \\
\hline GM283 family 4 & 0.026 & $176 / 178$ & 10 & 3 \\
\hline \multirow[t]{3}{*}{$(164 / 176 \times 176 / 178)$} & & $164 / 176$ & 2 & 7 \\
\hline & & $164 / 178$ & 1 & 4 \\
\hline & & $176 / 176$ & 2 & 1 \\
\hline
\end{tabular}

$\left(1=\right.$ the parental genotypes are given in brackets (dam x sire), ${ }^{2}=$ Fisher's exact probability, ${ }^{3}=$ allele sizes in base pairs) 


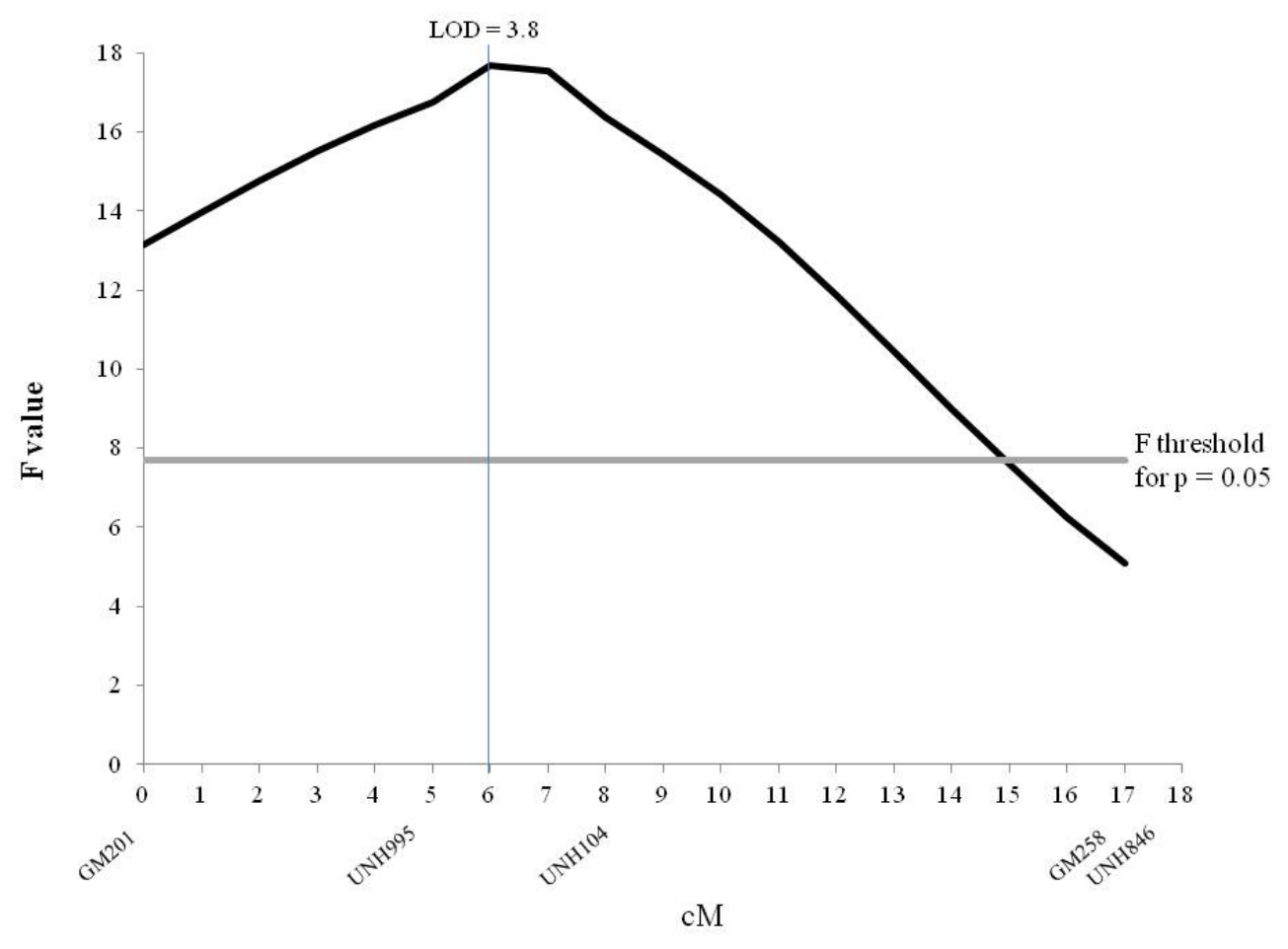

Figure 3. QTL statistics for LG 1 within family 6 of the $F_{1}$ mapping population.

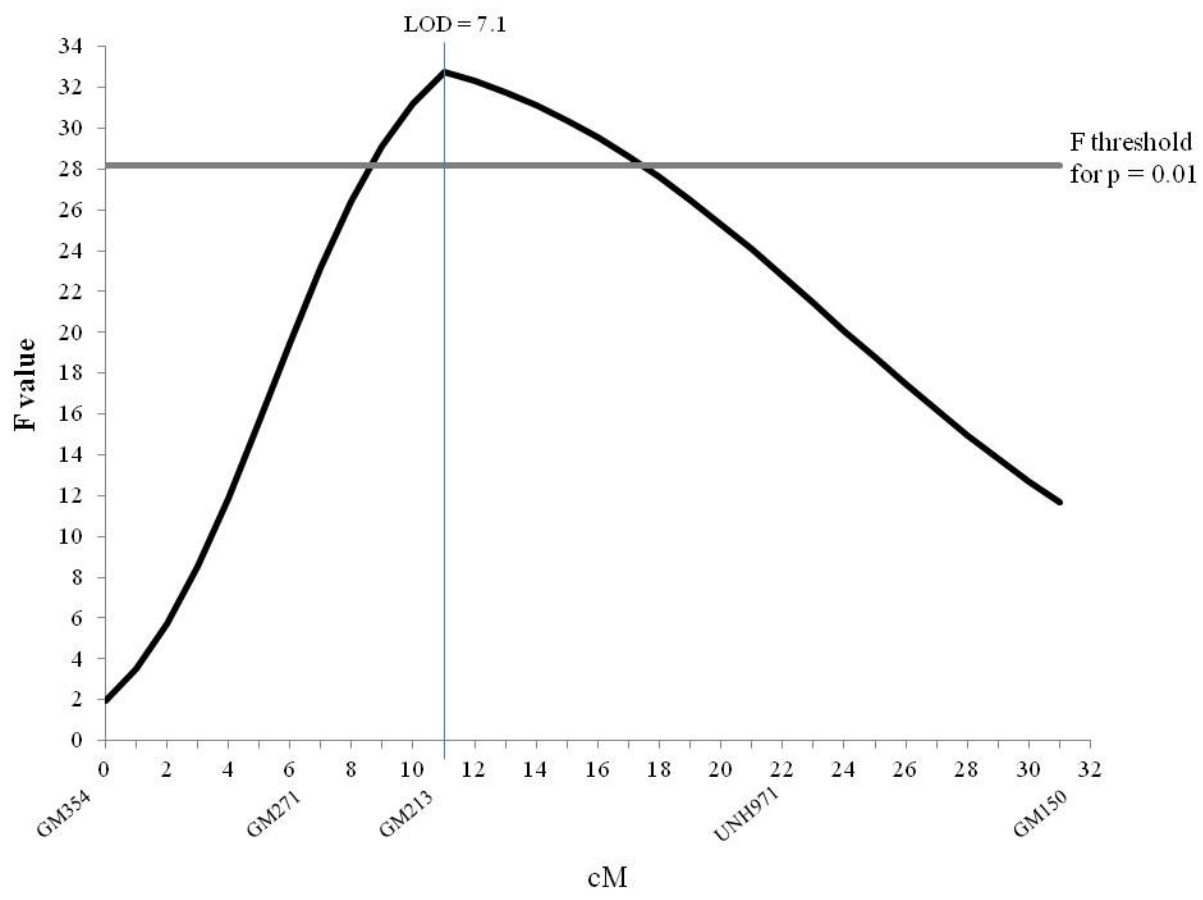

Figure 4. QTL statistics for LG 3a within family 2 of the $F_{1}$ mapping population. 


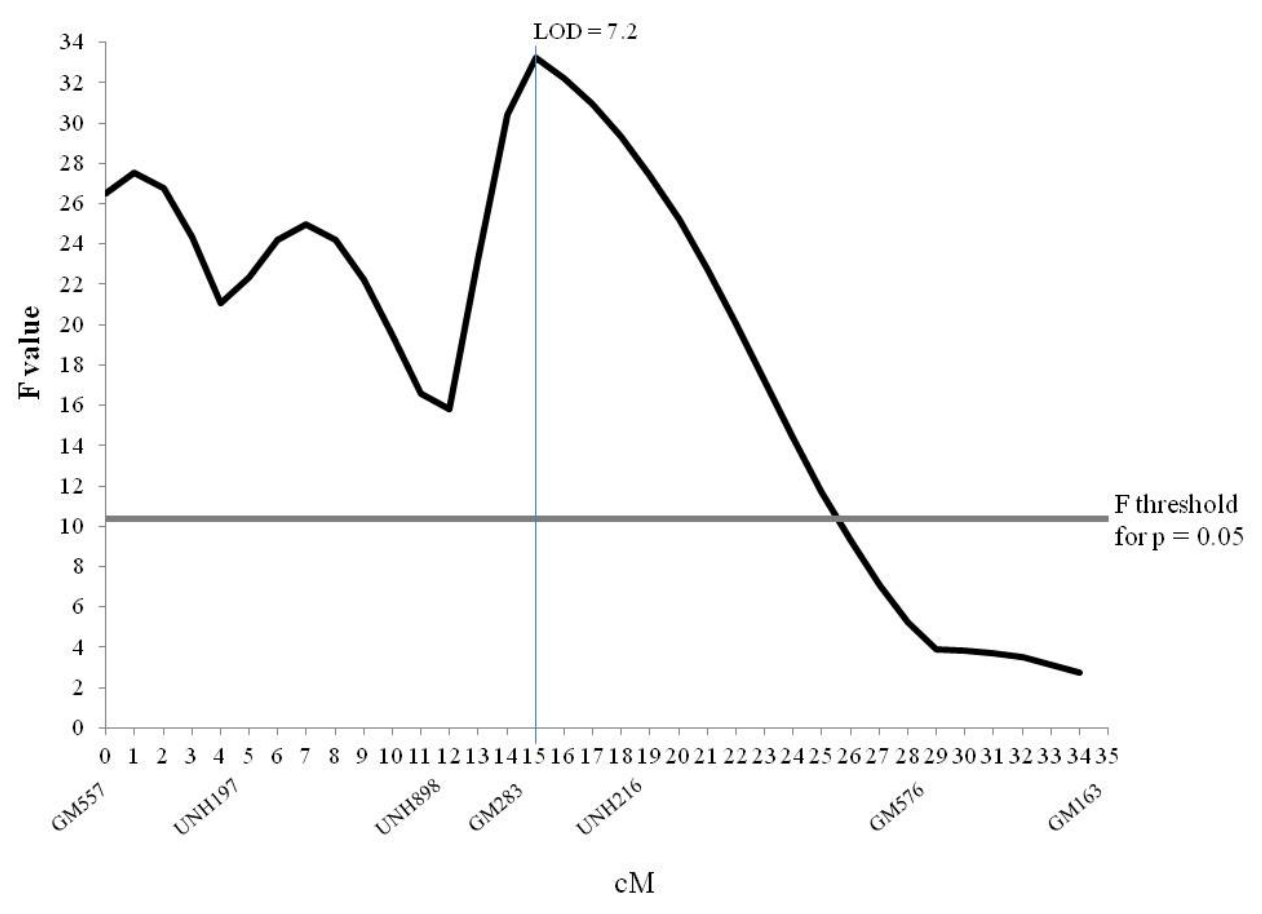

Figure 5. QTL statistics for LG 23 within family 4 of the $F_{1}$ mapping population.

\subsection{Discussion}

Previous studies have indicated that several genetic markers on LG 1, 3, and 23 are linked to the phenotypic sex of Oreochromis spp. (Shirak et al., 2002; Lee et al., 2003; 2004; 2005; 2011; Cnaani et al., 2004). Moreover, different genes which are putatively involved in the sex differentiation have also been mapped to these linkage groups (Lee et al., 2005; Shirak et al., 2006; Lee and Kocher 2007; Cnaani et al., 2008).

The current study is the first attempt to identify marker trait associations and QTL for the temperature-dependent phenotypic sex in a cichlid species with a sex determination system composed of major and minor genetic factors as well as clear temperature effects on the expression of the phenotypic sex.

\subsubsection{Phenotyping - temperature-dependent phenotypic sex}

In order to assure that all males observed in temperature-treated groups were temperature sex reversed, a genetically all-female population was used in the 
present study. This genetically all-female population was derived from a cross of a high $\left(\triangle \delta^{\lambda} \mathrm{XX}\right)$ and a low temperature sensitive line ( $\mathrm{XX}$ ) (Wessels and Hörstgen-Schwark, 2007; 2011). In the current study, no males were observed in five of the six control groups of the mapping population. Thus, autosomal sex factors can be excluded in these families. However, in the control group of family 6, two males out of 96 fish were found which might result from a sex reversal caused by autosomal factors. A contamination of the control groups by other fish is very unlikely as all aquaria were mesh covered to prevent jumping over of fish. Nevertheless, all males in the temperature-treated groups of family 6 were assumed to be temperature sex reversed.

\subsubsection{Marker properties}

Within the $F_{1}$ mapping population the microsatellites were highly informative. Both average values for Ho (0.68) and He (0.61) were moderately high, confirming their suitability for linkage and QTL mapping. Further, in the present study null alleles for several loci were observed (see Table 5). For GM271, also Cnaani and Kocher (2008) found null alleles in O. tanganicae and they discussed that the occurrence of null alleles indicates developing sex chromosomes. This has also been described for stickleback species (Gasterosteidae), where null alleles were shown to occur sex specifically as a sign of sex chromosome differentiation (Ross et al., 2009; Shikano et al., 2011). However, a sex specific occurrence of null alleles could not be reported here.

\subsubsection{Linkage mapping}

A comparison between the present linkage map and the reference map by Lee et al. (2005) revealed some differences. First of all, the linkage of GM633 and UNH985 to LG 1 could not be confirmed here (LOD $\leq 2$ ). Additionally, no linkage between both loci could be found in the present study; however, both markers were informative in the current mapping population. This lack of linkage may be due to the different fish species and populations used. Lee et al. (2005) worked with a species cross of $O$. niloticus and $O$. aureus whereas the present linkage map was constructed for an O. niloticus population. Additionally, the mapping population in the current study consisted of a genetically all-female (XX) popu- 
lation. The reported linkage of GM633 and UNH985 could thus have resulted from the mixed sex progeny of the crossed species.

Secondly, LG 3 was split in the present study, although the order of the loci persisted. Lee et al. (2005) reported a distance of 31 cM between GM150 and UNH106. In the present investigation, the distance could even be larger as no linkage between the markers was observed leading to LG 3a and LG 3b.

Thirdly, on LG 23 the loci UNH898 and GM283 switched in order compared to the map calculated by Lee et al. (2005). Again, species and population differences of the two studies might have attributed to the different results. Additionally, the current linkage groups (in $\mathrm{cM}$ ) were shorter compared to the proposed length of the reference map (see Figure 2).This may be due to the lower marker density for each linkage group as only a subset of the mapped markers was investigated in this study. Additionally, sex specific recombination rates might explain the differences in LG lengths. Higher recombination rates in the telomeric region of males and in the centromeric region of females have been described for several fish species like rainbow trout and zebrafish (Sakamoto et al., 2000, Singer et al., 2002). Also, Lee et al. (2004; 2005) observed different recombination rates for males and females in tilapia depending on the chromosomal region. Therefore, the current length of LGs could be specific for genetically female fish of $O$. niloticus.

\subsubsection{Marker trait associations for temperature-dependent phenotypic} sex

It is still controversially discussed if loci responsible for temperature-dependent sex and GSD reside on the same linkage groups, if they are located closely to each other, or if they are basically identical.

Sarre et al. (2004) proposed a continuum of GSD and temperature-dependent phenotypic sex, with the same genes involved in both systems within a species. In this study, no QTL on the population level were identified, but some were mapped for families 2, 4, and 6. The QTL were in the majority localized in regions with known associations between the phenotypic sexes at normal temperature. In family 6, significant associations to the temperature-dependent sex were found on LG 1 for the markers UNH995 (5 cM) and UNH104 (8.2 cM), con- 
firmed by a significant QTL (LOD=3.8) at the position of $6 \mathrm{cM}$ (Figure 2). For both markers the specific paternal alleles 220 (UNH995) and 178 (UNH104) were mostly found in males and might thus be suggested to be associated with phenotypic males after temperature treatment within this family. However, as not all of the male progenies possess these alleles; additional factors must control TSD in this family. In fact, the chromosomal region flanked by UNH995 and UNH104 harbors the major male sex determiner for O. niloticus (Cnaani et al., 2008). One putative key regulator for sex determination, the $w t 1 b$ gene has been mapped to LG $1,5.9 \mathrm{cM}$ away from UNH995 and $6.6 \mathrm{cM}$ away from UNH104. But it has been excluded as the major male determiner (Lee and Kocher, 2007). For tilapia, no temperature-dependent expression studies exist for $w t 1 b$.

In family 2 GM213 on LG 3a was significantly associated with the phenotypic sex, confirmed by a significant QTL on LG 3a at position of $11 \mathrm{cM}$ (Figure 2). In this family, most female progenies possessed the identical-by-state microsatellite alleles of the sire, whereas the identical-by-state alleles of the dam were mostly found in male progenies. For Oreochromis aureus, a tilapia species with a female heterogametic sex determination system (ZZ/WZ), maternally inherited alleles of LG 3 markers are assumed to be sex specific (Cnaani et al., 2008). Additionally, the gene $d m o$, which is involved in the gonadal development of the ovaries (Guan et al., 2000), has been mapped to the region between GM150 and UNH106 on LG 3, approximately 29 cM away from GM213 (Lee et al., 2005). Because of the large interval, a higher marker density should be applied to detect putative associations with the $d m o$ gene.

Moreover, significant associations with UNH898 on LG 23 were found in family 4 (Figure 3). Three different alleles for $\operatorname{UNH898}(254,262$, and 274) could be determined for this family. Progenies with the genotype 254/254 were male biased (10:4), whereas the genotype 254/274 produced almost all-females (1:4). If allele 262 was present, no association with the phenotypic sex could be observed. Therefore, it might be assumed, that each allele of UNH898 and their respective combinations represent a different liability to temperature within this family. Eshel et al. (2011) described the microsatellite marker UNH898 at LG 23 to be associated with the phenotypic sex of $O$. niloticus. The authors found 
allele 276 almost exclusively in males, and fish exhibiting genotypes with the alleles $253 / 253,253 / 274$, as well as $274 / 274$ were almost exclusively females. In the present study allele 276 was not detected. This could be reasonable, as a genetically all-female (XX) mapping population was used and no males in control groups were found. However, allele sizes strongly depend on the method of microsatellite analysis, as respective sizes in bp can differ between the techniques. Here, alleles were not sequenced and might therefore not be completely comparable. Thus, individuals that are homozygous for the allele 274 respectively for the allele 276 should comparatively be sequenced to assess the degree of identity.

Strong associations were found for GM283 on LG 23 in family 4. Ten out of 15 males showed the paternal genotype (176/178), whereas 12 out of 15 females were devoid of it. The QTL, detected for family 4 was mapped to $15 \mathrm{cM}$ (LOD=7.2), close to GM283 (14.5 cM). In family 4, segregation distortion was found for the genotypes of both microsatellites GM283 and UNH898 on LG 23. Cnaani et al. (2008) also reported deviations from the expected Mendelian segregation for sex-linked markers on LG 1 in 0 . aureus and 0 . mossambicus. The authors concluded that lethal alleles were linked to the sex determining factor. In the current mapping population no differences in mortality in dependence to the combination of alleles were detected after the $9^{\text {th }} \mathrm{dpf}$. If lethal alleles caused the segregation distortion in family 4, they would have had an impact on the survival before the $9^{\text {th }} \mathrm{dpf}$.

Different putative master key regulators for sex determination have been mapped to LG 23 (Shirak et al., 2002; 2006; Cnaani et al., 2007). Amh has been mapped to the position of GM283, just $1 \mathrm{cM}$ away from UNH898 (Shirak et al., 2002). Although amh exhibited a sex specific expression in brains of $14 \mathrm{dpf}$ old O. niloticus fry, there is no definite proof, that the expression of $a m h$ is also temperature-dependent (D'Cotta et al., 2007). Within other species, the role of $a m h$ in TSD is controversially discussed. Amh is involved in the regulation of cyp19a expression (Josso et al., 1998). Therefore, a temperature related expression of amh could be the result of a feedback effect of cyp19a expression (Pieau, 1996). Shirak et al. (2006) and Lee and Kocher (2007) mapped cyp19a to LG 1 between the microsatellites GM633 and UNH985. Both microsatellites could not be 
mapped to the present linkage map (Figure 2). Therefore, the QTL study could not cover this chromosomal region and no QTL or single marker-trait association could be found here. To achieve linkage in further experiments, a higher density of markers especially in this region should be realized.

No significant QTL or single marker association could be found for any of the markers in families 1, 3, and 5. Additionally, significant marker trait associations could not explain the temperature-dependent sex of all fish in the respective families. Therefore, it can be assumed, that additional family-specific QTL for the temperature-dependent phenotypic sex might be found on other LGs as well. D'Cotta et al. (2007) for example, provided a first evidence for a temperature-dependent expression of sox 9 in 0 . niloticus resulting in an earlier increase of sox9 expression in XX-gonads compared to XY-gonads. Moreover, dmrt1 expression is known to be up regulated by male producing temperature in different TSD-species like Trachemys scripta, Lepidochelys olivacea and Oryzias latipes (e.g. Kettlewell et al., 2000; Torres et al., 2002; Hattori et al., 2007). Dmrt1 has been mapped to LG 12 in tilapia (Lee et al., 2005). Hence, a genome-wide approach with special emphasis on chromosomal regions harboring candidate genes for sex determining processes seems to be promising.

The QTL detected herein correspond to regions known for sex determination at normal rearing temperature. Summarizing the controversial discussion about the interdependence of genetic and temperature effects on sex determination of vertebrates, Grossen et al. (2011) suggested for species with GSD, that the temperature effect is hidden by genes with major effects. But a certain threshold of liability values has to be exceeded (Grossen et al., 2011). This threshold model could also be suggested for the sex determination process in 0 . niloticus. A certain number of temperature-responsive allelic variants have to be exceeded, to result in phenotypic male differentiation during temperature treatments. This might be the reason, why not all progenies become male in a temperature treatment. Multiple interacting loci have also been postulated for autosomal sex determination in Nile tilapia (Müller-Belecke and Hörstgen-Schwark, 1995, Ser et al., 2010), yet the number of underlying QTL in both systems of sex determination remains to be determined. Therefore, temperature-dependent sex ex- 
pression in Nile tilapia might rather be a result of a polygenic system causing several liability values, which might overlap with liability values for GSD.

This is further underlined when looking at the allele inheritance of the significant markers in family 6. In which the sex determining allele came from the sire and was located on LG 1. Therefore factors influencing temperature and genetic effects on sex determination might at least partially reside in the same major sex determining region (LG1), also showing patterns of inheritance comparable to the XX/XY system for GSD. In contrast to that, the sex determining allele of GM213 in family 2 came from the dam and was located on LG 3 like in a WZ/ZZ system. The inheritance of sex determining alleles from LG 3 has never before been described for 0 . niloticus. However, studies about sex linked markers on LG 1 in 0 . niloticus reported missing linkage for markers on LG 1 (Lee et al., 2003; Ezaz et al., 2004). The sex determining loci on LG 3 may be an evolutionary rudiment because LG 3 has been suggested to be the ancestral sex chromosome and that sex determination loci has shifted to LG 1 (Cnaani et al., 2008). Shifts of sex determining loci from the ancestral sex chromosome to other LGs could also be the reason for the detected linkage of UNH898 and GM283 on LG 23 in family 4. Temperature effects on sex determination (and their absence) might play a crucial role in evolution and fixation of novel sex chromosomes or major sex factors as observed in Nile tilapia on LG1.

Moreover, only a single QTL has been found per family. Additionally, the QTL detected here were different for the families. Therefore, the chromosomal regions or genes on which the temperature acts seem to be dependent on the family. Because of the high variability of significant markers and QTL for the different families, it can be assumed, that the present mapping population will provide an excellent basis for further studies. Furthermore, the analysis of candidate genes is very promising, especially of amh and cyp19a. For both genes, polymorphisms have already been described for Oreochromis spp. (Shirak et al., 2006). Additionally, the microsatellite markers mostly show a high informativeness in this population which increases their suitability for further experiments. A following $\mathrm{F}_{2}$-population will provide additional segregations of the markers and QTL, including further LGs. Moreover, a higher accuracy and 
confirmation of the QTL positions is aimed to be achieved by using more markers in the current QTL regions.

\section{Acknowledgement}

The authors would like to thank Sabrina Pach and Birgit Reinelt for their technical assistance. This work was supported by the German Research Foundation (WE 4434/2-1). 


\subsection{References}

Baroiller, J. F., and D'Cotta, H. (2001): Environment and sex determination in farmed fish. Comparative Biochemistry and Physiology, 130, 399-409.

Baroiller, J.F., Chourrout, D., Fostier, A., Jalabert, B. (1995a): Temperature and sex-chromosomes govern sex ratios of the mouthbrooding cichlid fish Oreochromis niloticus. Journal of Experimental Zoology, 273, 216-223.

Baroiller, J.F., Clota, F., Geraz, E. (1995b): Temperature sex determination in two tilapia Oreochromis niloticus and the red tilapia (Red florida strain): Effect of high or low temperature, in Goetz FW, Thomas P (eds): Proceedings of the fifth international symposium on the reproductive physiology of fish. The University of Texas, Austin, Texas, USA, pp 158-160.

Bull J.J. (1980): Sex Determination in Reptiles. Quarterly Review of Biology, 55, 3-21.

Bull, J.J. (2008): Sex determination: are two mechanisms better than one? Journal of Biosciences, 33, 5-8.

Chomczynski, P. and Sacchi, N. (1987): Single-step method of RNA isolation by acid guanidinium thiocyanate-phenol-chloroform extraction. Analytical Biochemistry, 162:156-159.

Cnaani, A., and Kocher, T.D. (2008): Sex-linked markers and microsatellite locus duplication in the cichlid species Oreochromis tanganicae. Biology Letters, 4 700-703.

Cnaani, A., Zilberman, N., Tinman, S., Hulata, G., Ron, M. (2004): Genome-scan analysis for quantitative trait loci in an F2 tilapia hybrid. Molecular Genetics and Genomics, 272, 162-172.

Cnaani, A, Lee, B-Y., Ozouf-Costaz, C., Bonillo, C., Baroiller, J.F., D'Cotta, H., Kocher, T. (2007): Mapping of sox2 and sox14 in tilapia (Oreochromis spp.). Sexual Development, 1, 207-210.

Cnaani, A, Lee, B-Y., Zilberman, N., Ozouf-Costaz, C., Hulata, G., Ron, M., D’Hont, A., Baroiller, J.-F., D’Cotta, H., Penman, D.J., Tomasino, E., Coutanceau, J.-P., Pepey, E., Shirak, A., Kocher, T.D. (2008): Genetics of sex determination in tilapiine species. Sexual Development, 2, 43-54. 
D’Cotta, H., Fostier, A., Guiguen, Y., Govoroun, M., Baroiller, J.F. (2001): Aromatase plays a key role during normal and temperature-induced sex differentiation of tilapia Oreochromis niloticus. Molecular Reproduction and Development, 59, 265-276.

D’Cotta, H., Pepey, E., Pfennig, F., Bienvenu, D., Gutzeit, H.O., Volff, J.N., Wenning, M., Baroiller, J.F. (2007): Sox9a, Sox9b and Amh are up-regulated in the gonads during natural and temperature-induced tilapia male differentiation. In: Roudaut G, Labbé C, Bobe J (eds): Proceedings of the 8th International Symposium on Reproductive Physiology of Fish, Saint-Malo, France. pp 40.

Eshel, O., Shirak, A., Weller, J. I., Slossman, T., Hulata, G., Cnaani, A., Ron, M. (2011): Fine-mapping of a locus on linkage group 23 for sex determination in Nile tilapia (Oreochromis niloticus). Animal Genetics, 42, 222-224.

Ezaz, M.T., Harvey, S.C., Boonphakdee, C., Teale, A.J., McAndrew, B.J., Penman, D.J. (2004): Isolation and physical mapping of sex-linked AFLP markers in Nile tilapia (Oreochromis niloticus L.). Marine Biotechnology, 6, 435-445.

Grossen, C., Neuenschwander, S., Perrin, N. (2011): Temperature-dependent turnovers in sex-determination mechanisms: a quantitative model. Evolution, 65, 64-78.

Guan, G., Kobayashi, T., Nagahama, Y., (2000): Sexually dimorphic expression of two types of DM (Doublesex/Mab-3)-domain genes in a teleost fish, the Tilapia (Oreochromis niloticus). Biochemical and Biophysical Research Communications, 272, 662-666.

Guerrero, R.D. and Shelton, W.L. (1974): Aceto-carmine squash method for sexing juvenile fishes. Progressive Fish-Culturist, 36, 56-56.

Hattori, R.S., Gould, R.J., Fujioka, T., Saito, T., Kurita, J., Strüssmann, C.A., Yokota, M., Watanabe, S. (2007): Temperature-dependent sex determination in HdrR medaka Oryzias latipes: gender sensitivity, thermal threshold, critical period, and DMRT1 expression profile. Sexual Development, 1, 138-146.

Josso, N., Racine, C., di Clemente, N., Rey, R., Xavier, F. (1998): The role of antiMüllerian hormone in gonadal development. Molecular and Cellular Endocrinology, 145, 3-7. 
Kettlewell, J.R., Raymond, C.S., Zarkower, D. (2000): Temperature-dependent expression of turtle Dmrt1 prior to sexual differentiation. Genesis, 26, 174178.

Lee, B.-Y. and Kocher, T. D. (2007): Exclusion of Wilms tumour (WT1b) and ovarian cytochrome P450 aromatase (CYP19A1) as candidates for sex determination genes in Nile tilapia (Oreochromis niloticus). Animal Genetics, 38, 85-86.

Lee, B.-Y., Penman, D.J., Kocher, T.D. (2003): Identification of a sex-determining region in Nile tilapia (Oreochromis niloticus) using bulked segregant analysis. Animal Genetics, 34, 379-383.

Lee, B.-Y., Hulata, G., Kocher, T.D. (2004): Two unlinked loci controlling the sex of blue tilapia (Oreochromis aureus). Heredity, 92, 543-549.

Lee, B.-Y., Lee, W.-J., Streelman, J.T., Carleton, K.L., Howe, A.E, Hulata, G., Slettan, A., Stern, J.E., Terai, Y., and Kocher, T.D. (2005): A second-generation genetic linkage map of tilapia (Oreochromis spp.). Genetics, 170, 237-244.

Lee, B.Y., Coutanceau, J.P., Ozouf-Costaz, C., D’Cotta, H., Baroiller, J.F., Kocher, T.D. (2011): Genetic and physical mapping of sex-linked AFLP markers in Nile tilapia (Oreochromis niloticus). Marine Biotechnology, 13, 557-562.

Lühmann, L., Samavati, S., Wessels, S., Hörstgen-Schwark, G. (2009): The effect of temperature and hormone treatments during embryonic and post-larvae stages on sex differentiation in Nile tilapia (Oreochromis niloticus). Book of Abstracts of 10th International Symposium on Genetics in Aquaculture Bangkok, Thailand, June 22-26. 2009, p. 217.

Mair, G.C., Scott, A.G., Penman, DJ, Beardmore, J.A., Skibinski, D.O.E. (1991). Sex determination in the genus Oreochromis 1. Sex reversal, gynogenesis and triploidy in O. niloticus (L.). Theoretical and Applied Genetics, 144-152.

Müller-Belecke, A. and Hörstgen-Schwark, G. (1995): Sex determination in tilapia (Oreochromis niloticus) sex ratios in homozygous gynogenetic progeny and their offspring. Aquaculture, 137, 57-65.

Ospina-Alvarez, N. and Piferrer, F. (2008): Temperature-dependent sex determination in fish revisited: prevalence, a single sex ratio response pattern, and possible effects of climate change. PloS one 3, e2837. 
Pieau, C. (1996): Temperature variation and sex determination in reptiles. BioEssays, 18, 19-26.

Poonlaphdecha, S., Pepey, E., Huang, S.-H., Canonne, M., Soler, L., Mortaji, S., Morand, S., Pfennig, F., Mélard, C., and Baroiller, J.F. (2011): Elevated amh gene expression in the brain of male tilapia (Oreochromis niloticus) during testis differentiation. Sexual Development, 5, 33-47.

Ross, J.A., Urton, J.R., Boland, J., Shapiro, M.D., Peichel, C.L. (2009): Turnover of Sex Chromosomes in the Stickleback Fishes (Gasterosteidae). PLoS Genetics, 5, e1000391.

Sakamoto, T., Danzmann, R.G., Gharbi, K., Howard, P., Ozaki, A., Khoo, S.K., Woram, R.A., Okamoto, N., Ferguson, M.M., Holm, L.E., Guyomard, R., Hoyheim, B. (2000): A microsatellite linkage map of rainbow trout (Oncorhynchus mykiss) characterized by large sex-specific differences in recombination rates. Genetics 155, 1331-1345.

Sarre, S. D., Georges, A., Quinn, A. (2004): The ends of a continuum: genetic and temperature-dependent sex determination in reptiles. BioEssays, 26, 639645.

Seaton, G., Hernandez, J., Grunchec, J.A., White, I., Allen, J., De Koning, D.J., Wei, W., Berry, D., Haley, C., Knott, S. (2006): GridQTL: A Grid Portal for QTL mapping of compute intensive datasets, Proceedings of the 8th World Congress on Genetics Applied to Livestock Production August 13-18 2006. Belo Horizonte Brazil.

Ser, J.R., Roberts, R.B., Kocher, T.D.: Multiple interacting loci control sex determination in Lake Malawi cichlid fish. Evolution, 64, 486-501.

Shikano, T., Natri, H.M., Shimada, Y., Merilä, J. (2011): High degree of sex chromosome differentiation in stickleback fishes. BMC Genomics, 12, 474.

Shirak, A, Palti, Y., Cnaani, A., Korol, A., Hulata, G., Ron, M., Avtalion, R.R. (2002): Alleles and Distorted Sex Ratios in an Inbred Line of Tilapia (Oreochromis aureus). Journal of Heredity, 97, 270-276.

Shirak, A., Seroussi, E., Cnaani, A., Howe, A.E., Domokhovsky, R., Zilberman, N., Kocher, T.D., Hulata, G., Ron, M. (2006): Amh and Dmrta2 genes map to tilapia (Oreochromis spp.) linkage group 23 within quantitative trait locus regions for sex determination. Genetics, 174, 1573-1581. 
Shoemaker, C. M. and Crews, D. (2009): Analyzing the coordinated gene network underlying temperature-dependent sex determination in reptiles. Seminars in Cell and Developmental Biology, 20, 293-303.

Tessema, M., Müller-Belecke, A., and Hörstgen-Schwark, G. (2006): Effect of rearing temperatures on the sex ratios of Oreochromis niloticus populations. Aquaculture, 258, 270-277.

Torres Maldonado, L.C., Landa Piedra, A., Moreno Mendoza, N., Marmolejo Valencia, A., Meza Martínez, A., Merchant Larios, H. (2002): Expression profiles of Dax1, Dmrt1, and Sox9 during temperature sex determination in gonads of the sea turtle Lepidochelys olivacea. General and Comparative Endocrinology, 129, 20-26.

Van Ooijen, J.W. (2006): JoinMap® 4 Software for the calculation of genetic linkage maps in experimental populations. Kyazma B.V. Wageningen Netherlands.

Visscher, P.M. and Hopper, J.L. (2001): Power of regression and maximum likelihood methods to map QTL from sib-pair and DZ twin data. Annals of Human Genetics, 65, 583-601.

Voorrips, R.E. (2002): MapChart: Software for the graphical presentation of linkage maps and QTLs. Journal of Heredity, 93, 77-78.

Wessels, S. and Hörstgen-Schwark, G. (2007): Selection experiments to increase the proportion of males in Nile tilapia (Oreochromis niloticus) by means of temperature treatment. Aquaculture, 272, S80-S87.

Wessels, S. and Hörstgen-Schwark, G. (2011): Temperature-dependent sex ratios in selected lines and crosses with a YY-male in Nile tilapia (Oreochromis niloticus). Aquaculture, 318, 79-84. 
Chapter 4

General Discussion 


\subsection{Inheritance of sex ratios in 0 . niloticus}

Previous studies provided evidence that the temperature-dependent phenotypic sex of Nile tilapia strongly depends on the population and on the combination of the parental animals (Baroiller and D'Cotta, 2001; Tessema et al., 2006). In Chapter 2, additive, dominance and reciprocal effects for the temperature-dependent phenotypic sex of $O$. niloticus were estimated using complete testcross diallels of the divergently selected high and low temperature-susceptible lines (Wessels \& Hörstgen-Schwark, 2007; 2011). Additionally, heritabilities for the temperaturedependent sex ratios for both the high and low temperature susceptible line were estimates to be 0.74 and 0.52 for the high and low line, respectively. Previously, heritabilities of 0.26 for sex ratios of $O$. niloticus at normal rearing temperatures were estimated by Lester et al. (1989). Other studies estimated heritabilities for sex ratios in different species with approved temperature-dependent sex ratios as well. Rhen et al. (2011) estimated high heritabilities for the sexual phenotype of the leopard gecko (Eublepharis macularius) at two different temperatures producing different male ratios in this TSD-species. Vandeputte et al. (2007) estimated a heritability of $\mathrm{h}^{2}=0.62$ for the phenotypic sex of the European sea bass (Dicentrarchus labrax). In contrast to that, in the current study, the control groups, which were not treated with masculinising temperatures, the heritabilities for phenotypic sex at normal rearing temperatures were estimated to be close to zero and no effect on the sex ratios for both the high and low line could be detected in Chapter 2. This confirms the suggestion by Wessels and Hörstgen-Schwark (2007) that the selection for the temperature-dependent phenotypic sex was not correlated with a selection for phenotypic sex in general. Moreover, approximately no males were found in the control groups of the genetically all-female population (Chapter 3 ). Thus, it can be assumed that the selection for this trait is not correlated with autosomal factors, influencing the sex determination.

For the temperature-dependent male ratios a negative dominance effect for the low line has been found within both diallels which decreased in the diallel of the third generation. It can be suggested that major genetic factors influencing the sex determination have a stronger effect on the sex determining pathways and by 
ongoing selection, the effect decreases. Additionally, a decreasing reciprocal effect for the low line has been found from the first to the second diallel. The reciprocal effect in the first diallel was due to a maternal effect of the low line. However, the effect could not be found in the second diallel. Congruently with the previous assumption, the decreasing maternal effect can be suggested to be caused by an accumulation of factors for temperature-dependent sex determination in the population.

As a conclusion, in all conducted reciprocal line crosses, the sex ratios did not follow an additive genetic model, whereas this non-additive genetic effect decreased by ongoing selection.

\subsection{Polygenic sex determination}

According to previous studies and the assumptions of the current study (Chapter 2), the phenotypic sex of 0 . niloticus is in general subjected to a polygenic model. However, the sex ratios at normal ambient temperatures have a strong genetic background with low variation between different families and no maternal and paternal effects. Occurring family variations in sex ratios have mostly been assumed to be due to environmental factors, especially to temperature effects, acting on the sex determination (Lozano et al., 2011). Temperaturedependent sex ratios have been assumed to underlie a polygenic model because temperature-dependent sex ratios of progeny groups responded to selection (Wessels and Hörstgen-Schwark, 2007; 2011) and between family variations as well as maternal or paternal influences have been observed (Baroiller and Clota, 1998; Baroiller and D'Cotta, 2001; Tessema et al., 2006). In Chapter 2, evidence for a polygenic model of temperature-dependent sex ratios was provided. Dominance and reciprocal effects were detected for the high and low temperaturesusceptible lines. The reciprocal effect was supposed to be due to a maternal effect of the low line.

Moreover, the QTL analysis in Chapter 3 provides further evidence for a polygenic system of temperature-dependent sex reversal at the molecular genetic level. 
Three QTL for the temperature-dependent sex have been found on different LGs and further QTL on other linkage groups have been supposed. These observations provide evidence of the polygenic character of the temperature-driven sex determination in 0 . niloticus.

\subsection{Interaction of genetic sex determination and temperature ef- fects}

Temperature-dependent sex determination and genetic sex determination have long been considered as two fundamentally different traits which are mutually exclusive (Bull, 1980; Bull, 1985; Valenzuela et al., 2003). However, recent studies assume a co-existence of both systems with interactions of temperature and genetic effects, displaying a continuum (Sarre et al., 2004). In Nile tilapia, both genetic and temperature effects influence the phenotypic sex. Thus, a similar complex system of sex determination has been postulated (Wessels and Hörstgen-Schwark, 2007; Baroiller et al., 2009).

The present study is able to adduce evidence of this suggestion. In the first part of the current study, it has been assumed that the selection for a low susceptibility to temperature treatments leads to a stronger impact of the genetic factors for sex determination. Thus, the high line has been selected for a high susceptibility to temperature treatments connected to a low influence of genetic factors for sex determination by temperature treatments. Hence, both lines have been selected for the same trait, exhibiting a low or a high influence of masculinising temperatures on the sex determination pathway and the heritabilities for the temperature-dependent sex ratios in the low line are comparable with the heritabilities in the high line. Thus, both genetic and temperature effects co-exist in each family and each line.

In Chapter 3, additional evidence of this co-existence has been found at the molecular genetic level. The family-specific QTL for the temperature-dependent phenotypic sex were mainly localized in regions, where the major genetic factor for the phenotypic sex at normal temperatures has been mapped to in several 
studies (Shirak et al., 2002; Lee et al., 2003; 2004; 2005; 2011; Cnaani et al., 2004). Therefore, it can be stated out that the underlying genetic network for both systems is either connected or even congruent.

Grossen et al. (2011) suggested that in species with GSD, the temperature effect is hidden by genes with major effects. Furthermore, Ospina-Álvarez and Piferrer (2008) distinguished between species with real TSD and species with genotypic sex determination plus temperature effect (GSD + TE). Accordingly, sex determination in O. niloticus has to be defined as GSD + TE and elevated temperatures can have an influence on the phenotypic sex beside the existence of major genetic sex determining factors.

\subsection{A threshold model for sex determination}

In the previous chapters, it was shown that sex determination in 0 . niloticus is a polygenic trait with interacting genetic loci for the genetic and temperature effects. It was assumed, that the genetic and the temperature-dependent phenotypic sex underlie the same pathways and can be suggested to display essentially the same trait. This provides evidence, that sex determination of Nile tilapia underlies a threshold model with certain liability factors and is neither purely genetically nor environmentally determined but rather results from an interaction between the liability factors for both effects as proposed by Grossen et al. (2011).

The QTL detection provides evidence, that temperature effects on the phenotypic sex have a strong genetic background (Chapter 3), and it was shown that temperature response can be influenced by genetic factors and that maternal and paternal influences contribute to the trait (Chapter 2). The genetic components of sex determination have been assumed to consist of one major sex determiner (Jalabert et al., 1971; Mair et al., 1991) plus at least two minor genetic factors (Müller-Belecke and Hörstgen-Schwark, 1995). The temperature-dependent phenotypic sex has been proven to be a polygenic trait. Therefore, it can be suggested, that more and stronger liability factors for the temperature-driven sex are accumulated in the high line than in the low line. However, the connections and interactions of the liability factors are still questionable. The threshold may be 
addicted to the quantity of factors on the one hand or to the quality of the liability factors on the other hand.

High temperature-dependent male ratios may be due to an accumulation of temperature liability factors at the population (Chapter 2) and the individual level (Chapter 3). Furthermore, the genetic components of temperature liability factors seemed to overlap with major and minor genetic factors of sex determination. Therefore, liability factors for temperature-dependent phenotypic sex could rather be due to allelic interactions and differentially expressed sex-determining genes, directly or indirectly influenced by temperatures.

\subsection{Concluding remarks and outlook}

Investigations of sex determination and sex ratios offer some of the best opportunities for studying the nature of constraints of adaptation and evolution by natural selection and are therefore of fundamental importance for biological and evolutionary sciences (e.g. West et al., 2002; Sarre et al., 2004).

The present study provides decisive information about the genetic background of sex determination in 0 . niloticus. Results of this study enable interesting insights in the formation of temperature-dependent sex ratios and sex reversal.

Following research on QTL for the temperature-driven sex in Nile tilapia should aim to provide stronger segregation patterns using a consecutive $F_{2}$-population of the line crosses. A fine mapping of the located QTL as well as the analysis of further linkage groups seems very promising. Temperature-dependent expression analysis of candidate genes will provide stronger information about the sex determination cascade and the interactions between genetic and temperature effects on the phenotypic sex of Nile tilapia.

In summary, substantial progress has been achieved for establishing prospective breeding programs for temperature-induced masculinisation in order to substitute hormone treatments in tilapia production systems. The study provides the first step for the development of a marker-assisted selection for high male ratios by temperature treatments. 


\subsection{References}

Baroiller, J.F. and Clota, F. (1998): Interactions between temperature effects and genotype on Oreochromis niloticus sex determination. Journal of Experimental Zoology, 281, 507 (abstract).

Baroiller, J.F., and D'Cotta, H. (2001): Environment and sex determination in farmed fish. Comparative Biochemistry and Physiology, 130, 399-409.

Baroiller, J.F., D'Cotta, H., Bezault, E., Wessels, S., Hörstgen-Schwark, G. (2009): Tilapia sex determination: Where temperature and genetics meet. Comparative Biochemistry and Physiology, 153, 30-38.

Bull J.J. (1980): Sex Determination in Reptiles. Quarterly Review of Biology, 55, 3-21.

Bull, J.J. (1985): Sex Ratio and Nest Temperature in Turtles: Comparing Field and Laboratory Data. Ecology, 66, 1115-1122.

Cnaani, A., Zilberman, N., Tinman, S., Hulata, G., Ron, M. (2004): Genome-scan analysis for quantitative trait loci in an F2 tilapia hybrid. Molecular Genetics and Genomics, 272, 162-172.

Grossen, C., Neuenschwander, S., Perrin, N. (2011): Temperature-dependent turnovers in sex-determination mechanisms: a quantitative model. Evolution, 65, 64-78.

Jalabert, B., Kammacher, P., Lessent, P. (1971): Déterminisme du sexe chez les hybrides entre tilapia macrochir et tilapia nilotica. étude de la sex-ratio dans les recroisements des hybrides de premiere génération par les espèces parentes. Annales de Biologie Animale Biochimie Biophysique, 11, 155-165.

Lee, B.-Y. and Kocher, T.D. (2007): Exclusion of Wilms tumour (WT1b) and ovarian cytochrome P450 aromatase (CYP19A1) as candidates for sex determination genes in Nile tilapia (Oreochromis niloticus). Animal Genetics, 38, 8586.

Lee, B.-Y., Penman, D.J., Kocher, T.D. (2003): Identification of a sex-determining region in Nile tilapia (Oreochromis niloticus) using bulked segregant analysis. Animal Genetics, 34, 379-383. 
Lee, B.-Y., Hulata, G., Kocher, T.D. (2004): Two unlinked loci controlling the sex of blue tilapia (Oreochromis aureus). Heredity, 92, 543-549.

Lee, B.-Y., Lee, W.-J., Streelman, J.T., Carleton, K.L., Howe, A.E, Hulata, G., Slettan, A., Stern, J.E., Terai, Y., Kocher, T.D. (2005): A second-generation genetic linkage map of tilapia (Oreochromis spp.). Genetics, 170, 237-244.

Lee, B.Y., Coutanceau, J.P., Ozouf-Costaz, C., D’Cotta, H., Baroiller, J.F., Kocher, T.D. (2011): Genetic and physical mapping of sex-linked AFLP markers in Nile tilapia (Oreochromis niloticus). Marine Biotechnology, 13, 557-562.

Lester, L., Lawson, K., Abella, T., Palada, M. (1989): Estimated heritability of sex ratio and sexual dimorphism in tilapia. Aquaculture Research, 20, 369-380.

Lozano, C., Gjerde, B., Bentsen, H.B., Dionisio, E.E., Rye, M. (2011): Estimates of strain additive genetic, heterosis and reciprocal effects for male proportion in Nile tilapia, Oreochromis niloticus L. Aquaculture, 312, 32-42.

Mair, G.C., Scott, A.G., Penman, D.J, Beardmore, J.A., Skibinski, D.O.E. (1991). Sex determination in the genus Oreochromis 1 . Sex reversal, gynogenesis and triploidy in O. niloticus (L.). Theoretical and Applied Genetics, 82, 144-152.

Müller-Belecke, A. and Hörstgen-Schwark, G. (1995): Sex determination in tilapia (Oreochromis niloticus) sex ratios in homozygous gynogenetic progeny and their offspring. Aquaculture, 137, 57-65.

Ospina-Alvarez, N. and Piferrer, F. (2008): Temperature-dependent sex determination in fish revisited: prevalence, a single sex ratio response pattern, and possible effects of climate change. PloS one, 3, e2837.

Rhen, T., Schroeder, A., Sakata, J.T., Huang, V., Crews, D. (2011): Segregating variation for temperature-dependent sex determination in a lizard, Heredity, $106,649-660$.

Sarre, S. D., Georges, A., Quinn, A. (2004): The ends of a continuum: genetic and temperature-dependent sex determination in reptiles. BioEssays, 26, 639645.

Shirak, A, Palti, Y., Cnaani, A., Korol, A., Hulata, G., Ron, M., and Avtalion, R.R. (2002): Alleles and Distorted Sex Ratios in an Inbred Line of Tilapia (Oreochromis aureus). Journal of Heredity, 97, 270-276. 
Tessema, M., Müller-Belecke, A., Hörstgen-Schwark, G. (2006): Effect of rearing temperatures on the sex ratios of Oreochromis niloticus populations. Aquaculture, 258, 270-277.

Valenzuela, N., Adams, D.C., Janzen, F.J. (2003): Pattern does not equal process: exactly when is sex environmentally determined? The American Naturalist, 161, 676-683.

Vandeputte, M., Dupont-Nivet, M., Chavanne, H., Chatain, B. (2007): A polygenic hypothesis for sex determination in the European sea bass Dicentrarchus labrax. Genetics, 176, 1049-1057.

Wessels, S. and Hörstgen-Schwark, G. (2007): Selection experiments to increase the proportion of males in Nile tilapia (Oreochromis niloticus) by means of temperature treatment. Aquaculture, 272, S80-S87.

Wessels, S. and Hörstgen-Schwark, G. (2011): Temperature-dependent sex ratios in selected lines and crosses with a YY-male in Nile tilapia (Oreochromis niloticus). Aquaculture, 318, 79-84.

West, S.A., Reece, S.E., Sheldon, B.C. (2002): Sex Ratios. Heredity, 88, 117-124. 


\section{Curriculum vitae}

\section{Liane-Magdalena Lühmann}

\section{Personal Details}

Date of birth December 09, 1983

Place of birth Celle, Germany

Nationality German

Professional experience

Since 04/2012 Research Assistant at the Department of Animal Sciences, Division of Reproduction and Biotechnology of Livestock and Division of Aquaculture and Aquatic Ecology at the Georg-August University of Göttingen

10/2008-12/2011 Research Assistant at the Department of Animal Sciences, Division of Aquaculture and Water Ecology at the GeorgAugust University of Göttingen

04/2007-04/2008 Student Research Assistant at the Institute of Animal Physiology and Nutrition at the Georg-August University of Göttingen

02/2006-04/2006 Internship at the Institute of Animal Welfare and Animal Husbandry (Friedrich-Loeffler-Institute; Federal Research Institute for Animal Health, Celle)

Work experience abroad

06/2009-07/2009 Chiang Mai Inland Fisheries Research and Development Centre, Thailand

Studies on temperature dependent sex determination in Nile tilapia (Oreochromis niloticus), within a DAAD sponsored partnership between the Universities of Göttingen and Chiang Mai

Education

10/2006-09/2008 Master's program for Agricultural Sciences with emphasis in Animal Sciences at the Georg-August University of Göttingen,

Degree: Master of Science

10/2003-09/2006 Bachelor's program for Agricultural Sciences with emphasis in Animal Sciences at the Georg-August University of Göttingen, Degree: Bachelor of Science 


\section{Acknowledgement - Danksagung}

Frau Prof. Dr. G. Hörstgen-Schwark danke ich für die Überlassung des Themas sowie für die Betreuung, die Unterstützung und viel Zuspruch bei der Anfertigung dieser Arbeit.

Bei Herrn Prof. Dr. C. Knorr bedanke ich mich für die Übernahme des Korreferats sowie für seine sehr tolle Betreuung und Unterstützung nicht nur während der Markeranalysen.

Herrn Dr. S. Wessels danke ich für die angenehme Zusammenarbeit, wissenschaftliche Diskussionen sowie für viel Zeit und Engagement, die er aufgewendet hat um diese Doktorarbeit zu ermöglichen.

Herrn Prof. Dr. Sven König danke ich zum einen für die Übernahme des zweiten Korreferats sowie für die Zusammenarbeit bei der Erstellung des Pedigrees und bei der Schätzung der genetischen Effekte und Heritabilitäten.

Herrn Dr. Eduardo Pimentel danke ich außerordentlich für seine Kompetenz und viel Geduld bei den Berechnungen der Heritabilitäten und der genetischen Effekte.

Herrn Prof. Dr. Dr. B. Brenig danke ich dafür, dass ich die Laborbereiche nutzen durfte.

Mein großer Dank gilt allen Mitarbeitern der Arbeitsgruppe Aquakultur und Gewässerökologie. Wir haben viele schöne und nasse Stunden miteinander verbracht. Dabei gilt mein Dank vor allem Uwe Schipke, Hannah Mruck und Jakob Gährken für viel Hilfe beim Fische aufziehen und sexen.

Besonders möchte ich mich bei Brigit Reinelt bedanken, von der ich so viel lernen durfte und die mir immer geholfen und beigestanden hat.

Außerdem danke ich Dr. Stefanie Ohlemeyer for beeing the best office mate, ever! Danke, für Duplo, Tee, viele Korrekturen und Unterstützung in jeglicher Hinsicht.

Allen Mitarbeitern der Arbeitsgruppe Reproduktion und Biotechnologie sowie Molekularbiologie und Genetik danke ich für meine schöne Zeit im Labor. Ihr seid eine tolle Truppe und ich bin stolz darauf, dass ich dazu gehör.

Vor allem möchte ich mich bei Sabrina Pach bedanken, ohne deren Geduld, Fachkompetenz und Unermüdlichkeit diese Arbeit niemals zustande gekommen wäre.

Vielen Dank an Magdalena Hofmann, für tolle Gespräche, für weniger additionallys und für ihre Freundschaft.

Meiner Mutter und meinen Geschwistern danke ich für stundenlanges zuhören, aufbauen und mitfreuen! Ohne Eure Unterstützung wäre es nur halb so schön gewesen!!!

Torben Schulz-Streeck danke ich für seine Liebe, für seine Ruhe und Kraft und für seine Hilfe bei der Fertigstellung der Arbeit! 